Check for updates

Cite this: Phys. Chem. Chem. Phys., 2018, 20, 4020

Received 9th November 2017, Accepted 9th January 2018

DOI: $10.1039 / c 7 c p 07584 g$

rsc.li/pccp

\section{The oxidation of sulfur(Iv) by reaction with iron(III): a critical review and data analysis}

\begin{abstract}
Peter Warneck (D)
The dependences on ionic strength of the hydrolysis constants of $\mathrm{Fe}^{3+}$ and of the first dissociation constant of sulfurous acid are briefly reviewed. The data are needed to derive from apparent stability constants reported in the literature the stability constants for the three iron-sulfito complexes defined by the equilibria (c1) $\mathrm{FeOH}^{2+}+\mathrm{HSO}_{3}^{-}=\mathrm{FeSO}_{3}{ }^{+}+\mathrm{H}_{2} \mathrm{O}$, (c2) $\mathrm{FeSO}_{3}{ }^{+}+\mathrm{HSO}_{3}{ }^{-}=\mathrm{Fe}\left(\mathrm{SO}_{3}\right)_{2}{ }^{-}+\mathrm{H}^{+}$, (c3a) $\mathrm{Fe}\left(\mathrm{SO}_{3}\right)_{2}{ }^{-}+\mathrm{HSO}_{3}{ }^{-}=\mathrm{Fe}\left(\mathrm{SO}_{3}\right)_{3} \mathrm{H}^{2-}$, where $K_{\mathrm{c} 1}=1982 \pm 518 \mathrm{dm}^{3} \mathrm{~mol}^{-1}, K_{\mathrm{c} 2}=0.72 \pm 0.08, K_{\mathrm{c} 3 a}=189 \pm$ $9 \mathrm{dm}^{3} \mathrm{~mol}^{-1}$ (ionic strength $\mu=0.1 \mathrm{~mol} \mathrm{dm}^{-3}$ ). The rapid formation of these complexes is followed by a slower decomposition leading to the formation of $\mathrm{SO}_{3}{ }^{-}$radicals; the associated rate coefficients are $k_{1}=0.19 \mathrm{~s}^{-1}, k_{1 \mathrm{a}} \approx 0.04 \mathrm{~s}^{-1}$, and $k_{1 \mathrm{~b}} \approx 0.08 \mathrm{~s}^{-1}$, respectively. The subsequent reaction leads to dithionate and sulfate as products. Overall rates and product yields from a variety of studies of the slow reaction are found to be consistent with a mechanism, in which the production of dithionate occurs mainly by the reaction of $\mathrm{SO}_{3}{ }^{-}$with $\mathrm{FeSO}_{3}{ }^{+}$and that of sulfate by the reaction of $\mathrm{SO}_{3}{ }^{-}$with $\mathrm{FeOH}^{2+}$ and/or $\mathrm{Fe}^{3+}$. The role of copper as a catalyst is also analyzed. Rate coefficients for individual reactions are estimated from the data at low $\mathrm{pH}\left(\mu=1.0 \mathrm{~mol} \mathrm{dm}^{-3}\right)$ under conditions where the 1:1-complex is prevalent. They are extrapolated to lower ionic strengths for an analysis of the data obtained at higher $\mathrm{pH}$ to explore conditions when reactions of the higher complexes become important. The overall rate and the product yields of the reaction depend critically on the $\mathrm{pH}$, the initial ratio of $\mathrm{S}(\mathrm{IV})$ to Fe(III) and the ionic strength of the solution.
\end{abstract}

\section{Introduction}

Iron belongs to a group of transition metals that are known to catalyze the oxidation of S(Iv) in aqueous solution. ${ }^{1}$ Such reactions are of interest especially in the atmospheric sciences because they are predicted to occur in the aqueous phase of clouds and fogs, where they would contribute to the removal of $\mathrm{SO}_{2}$ from the atmosphere. ${ }^{1-3}$ Thus, it is not surprising that the Fe(III)-catalyzed oxidation of S(Iv) in aerated aqueous solutions has been studied in much detail. ${ }^{1}$ A consistent chemical mechanism was developed, ${ }^{4,5}$ which incorporates a chain reaction carried by sulfuroxy radicals, and rate coefficients are available for most of the individual reactions involved. ${ }^{6-8}$ But Fe(III) is known to oxidize S(Iv) also in the absence of oxygen. Far fewer studies have dealt with this process, ${ }^{9-16}$ and no consensus has been reached regarding the relevant mechanism. This reaction in de-aerated solutions is the subject of the present critical analysis.

There is agreement that the reaction is initiated by the formation of one or more iron-sulfito complexes. The presence of such complexes is indicated by the appearance, and the subsequent fading, of a reddish brown color when a solution containing $\mathrm{Fe}(\mathrm{III})$ is mixed with another solution containing

Max-Planck Institute for Chemistry, Hahn-Meitner Weg 1, 55128 Mainz, Germany. E-mail: Peter.Warneck@gmx.de
S(Iv). Stopped flow spectrophotometry has been used to follow the formation and decay of the complexes. ${ }^{14-17}$ Measurements at short reaction times suggest the existence of three complexes resulting from the successive addition to $\mathrm{Fe}(\mathrm{III})$ of $\mathrm{S}$ (IV) as ligand. ${ }^{17,19,20}$ Absorbance changes due to the variation of S(Iv) concentrations have been exploited to derive apparent stability constants for the complexes under various experimental conditions. ${ }^{14,17-19}$ Unfortunately, the results have never been subjected to a detailed analysis, so that the true stability constants are still not available. The slower subsequent reaction, which leads to $\mathrm{Fe}(\mathrm{II}), \mathrm{S}(\mathrm{v})$ and $\mathrm{S}(\mathrm{VI})$ as products, has been studied by product analysis under conditions when the reaction is sufficiently slow. ${ }^{9-14}$ In reviewing these publications I have found that the modification of a simple reaction mechanism first proposed by Higginson and Marshall ${ }^{9}$ can explain most if not all of the experimental results.

Fundamental to an analysis of all experimental data is a knowledge of the speciation of $\mathrm{Fe}(\mathrm{III})$ and $\mathrm{S}$ (IV) resulting from the hydrolysis of $\mathrm{Fe}^{3+}$ and $\mathrm{SO}_{2 \mathrm{aq}}$, respectively, and their dependence on $\mathrm{pH}$ and ionic strength. This makes it necessary to review briefly the hydrolysis constants of iron, and the first dissociation constant of sulfurous acid. Whereas the ionic strength dependences of the iron hydrolysis constants are quite well known, that of the dissociation constant of sulfurous acid appears to have not been well defined in the literature so that it 
needs to be re-examined. Following these preliminaries the data available for the apparent stability constants of the $\mathrm{Fe}(\mathrm{III})-\mathrm{S}$ (Iv) complexes are reviewed, the true stability constants are derived, and rate coefficients of their formation are discussed. The results are then used in the subsequent analysis of the experimental data reported for the slower reaction, which follows the decomposition of the complexes. In addition to making use of functional relationships in evaluating the experimental data, computer simulations were carried out aiming to reproduce the experimental data.

\section{Iron(III) in aqueous solution}

Trivalent iron, $\mathrm{Fe}^{3+}$, undergoes hydrolysis in aqueous solution whereby $\mathrm{FeOH}^{2+}, \mathrm{Fe}(\mathrm{OH})_{2}{ }^{+}$, and $\mathrm{Fe}_{2}(\mathrm{OH})_{2}{ }^{4+}$ are formed as products. The sum of all species and the total concentration will be designated $\mathrm{Fe}(\mathrm{III})$ and $\left[\mathrm{Fe}_{\mathrm{III}}\right]_{\text {tot }}$, respectively. The relative concentrations of the different species are determined by equilibria that depend on the $\mathrm{pH}$, the ionic strength and the total concentration. In acidic solutions the solubility of $\mathrm{Fe}(\mathrm{III})$ decreases with increasing $\mathrm{pH}$; the final hydrolysis product $\mathrm{Fe}(\mathrm{OH})_{3}$ is the least soluble. Precipitation sets in at $\mathrm{pH}>4$, even at low concentrations, so that experimental studies of $\mathrm{Fe}(\mathrm{III})$ are restricted to the more acidic $\mathrm{pH}$ regime. At $\mathrm{pH} 2-3$ the major species are $\mathrm{Fe}^{3+}$ and $\mathrm{FeOH}^{2+}$. The extent of dimer formation can be minimized by keeping $\left[\mathrm{Fe}_{\mathrm{III}}\right]_{\text {tot }}$ below $1 \mathrm{mmol} \mathrm{dm}^{-3}$. Under such conditions the dominant equilibrium is

$$
\begin{gathered}
\mathrm{Fe}^{3+}+\mathrm{H}_{2} \mathrm{O}=\mathrm{FeOH}^{2+}+\mathrm{H}^{+} \\
K_{\mathrm{h} 1}=\left[\mathrm{FeOH}^{2+}\right]\left[\mathrm{H}^{+}\right] /\left[\mathrm{Fe}^{3+}\right]
\end{gathered}
$$

The $\mathrm{H}_{2} \mathrm{O}$ molecule causing the hydrolysis is taken from the hydration sphere of $\mathrm{Fe}^{3+}$. In the following, the hydration sphere will be neglected, however. Fig. 1 shows $K_{\mathrm{h} 1}$ as a function of ionic strength at $25{ }^{\circ} \mathrm{C}$. Points are values obtained from

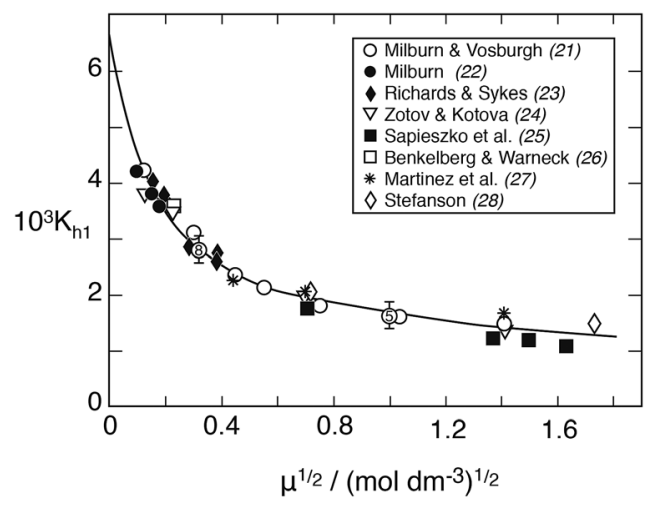

Fig. 1 The first hydrolysis constant of Fe(III) versus the root of ionic strength in $\mathrm{NaClO}_{4}$ medium at $25{ }^{\circ} \mathrm{C}$ derived from spectrophotometric measurements. To avoid crowding, the points at $\mu^{\frac{1}{2}}=0.316$ and 1.0 are shown as averages: the former includes 8 values from the authors listed plus Knight and Sylva, ${ }^{29}$ the latter includes five values. The solid line is calculated from eqn (1). spectrophotometric measurements - conducted mainly at $340 \mathrm{~nm}$ wavelength - and the solid line represents the best fit to the extended Debye-Hückel equation

$$
\log K_{\mathrm{h} 1}=\log { }^{0} K_{\mathrm{h} 1}-2.04 \mu^{\frac{1}{2}} /\left(1+2.4 \mu^{\frac{1}{2}}\right)-0.01 \mu,
$$

where $\log { }^{0} K_{\mathrm{h} 1}=-2.174$ is obtained by extrapolation. The numerical parameters in this equation were originally suggested by Milburn and Vosburgh, ${ }^{21}$ whose measurements covered ionic strengths up to $\mu=3.0$. While spectrophotometry has been the favored measurement technique, potentiometric titration has also been applied, based on measuring simultaneously the hydrogen ion concentration and the $\mathrm{Fe}^{3+} / \mathrm{Fe}^{2+}$ redox potential. By means of computer-assisted analyses of the titration curves, Byrne et al. ${ }^{30}$ and Stefanson ${ }^{28}$ have obtained results in perfect agreement with those of Milburn and Vosburgh. ${ }^{21}$

Whereas the dependence on ionic strength of the first hydrolysis constant is well documented, measurements of the second hydrolysis constant are still sparse. The equilibrium may be written in two ways:

$$
\begin{gathered}
\mathrm{Fe}^{3+}+2 \mathrm{H}_{2} \mathrm{O}=\mathrm{Fe}(\mathrm{OH})_{2}^{+}+2 \mathrm{H}^{+} \\
\mathrm{FeOH}^{2+}+\mathrm{H}_{2} \mathrm{O}=\mathrm{Fe}(\mathrm{OH})_{2}^{+}+\mathrm{H}^{+} \\
K_{\mathrm{h} 2}=\left[\mathrm{Fe}(\mathrm{OH})_{2}^{+}\right]\left[\mathrm{H}^{+}\right]^{2} /\left[\mathrm{Fe}^{3+}\right] \\
K_{\mathrm{h} 2 \mathrm{a}}=\left[\mathrm{Fe}(\mathrm{OH})_{2}^{+}\right]\left[\mathrm{H}^{+}\right] /\left[\mathrm{FeOH}^{2+}\right]
\end{gathered}
$$

Both equilibrium constants are related in that $K_{\mathrm{h} 2 \mathrm{a}}=$ $K_{\mathrm{h} 2} / K_{\mathrm{h} 1}$. The first expression is prevalent in the literature, however. Early attempts to determine the equilibrium constant by means of potentiometric titration ${ }^{25,31,32}$ gave results that scattered over a wide range. Then Byrne et $a l .{ }^{30}$ critically reviewed the data and concluded that potentiometric titration is not sufficiently sensitive and unsuitable for the determination of $K_{\mathrm{h} 2}$. On the other hand, more recent optical absorption studies over an extended range of $\mathrm{pH}$ have revealed a spectrum that was assigned, ${ }^{28,33,34}$ to $\mathrm{Fe}(\mathrm{OH})_{2}{ }^{+}$. This made the determination of $K_{\mathrm{h} 2}$ by means of spectrophotometry possible. Stefansson ${ }^{28}$ has summarized the available data and suggested an ionic strength dependence

$$
\log K_{\mathrm{h} 2}=\log { }^{0} K_{\mathrm{h} 2}-3.06 \mu^{\frac{1}{2}} /\left(1+1.58 \mu^{\frac{1}{2}}\right)
$$

where $\log { }^{0} K_{\mathrm{h} 2}=-5.76 \pm 0.06$ was again obtained by extrapolation. This value, as well as that in the denominator of the second term, is still uncertain because of an insufficient number of data available at low ionic strengths.

The equilibrium constant of the $\mathrm{Fe}_{2}(\mathrm{OH})_{2}{ }^{4+}$ complex may also be defined in two ways:

$$
\begin{gathered}
\mathrm{Fe}^{3+}+2 \mathrm{H}_{2} \mathrm{O}=\mathrm{Fe}_{2}(\mathrm{OH})_{2}{ }^{4+}+2 \mathrm{H}^{+} \\
\mathrm{FeOH}^{2+}+\mathrm{FeOH}^{2+}=\mathrm{Fe}_{2}(\mathrm{OH})_{2}{ }^{4+} \\
K_{\mathrm{h} 3}=\left[\mathrm{Fe}_{2}(\mathrm{OH})_{2}{ }^{4+}\right]\left[\mathrm{H}^{+}\right]^{2} /\left[\mathrm{Fe}^{3+}\right] \\
K_{\mathrm{h} 3 \mathrm{a}}=\left[\mathrm{Fe}_{2}(\mathrm{OH})_{2}{ }^{4+}\right] /\left[\mathrm{FeOH}^{2+}\right]^{2}
\end{gathered}
$$




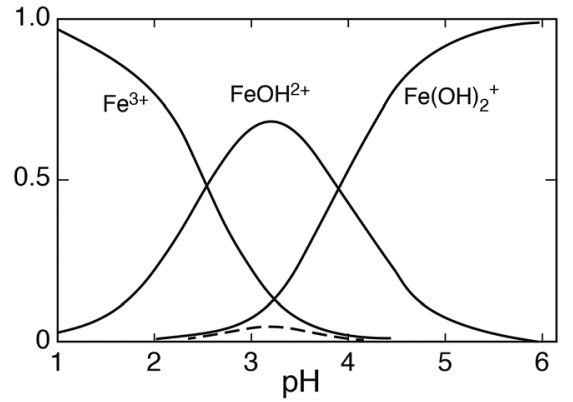

Fig. 2 The distribution of $\mathrm{Fe}(\mathrm{II})$ hydrolysis species as a function of $\mathrm{pH}$, $\left[\mathrm{Fe}_{\mid I I}\right]=0.5 \mathrm{mmol} \mathrm{dm}{ }^{-3}, \mu=0.1$; the broken line represents $\mathrm{Fe}_{2}(\mathrm{OH})_{2}{ }^{4+}$.

The first of these is preferred because it is nearly independent of ionic strength, whereas the second varies strongly with it. According to Stefansson ${ }^{28}$

$$
\log K_{\mathrm{h} 3}=\log { }^{0} K_{\mathrm{h} 3}+0.022 / \mu^{\frac{1}{2}}
$$

where $\log { }^{0} K_{\mathrm{h} 3}=-2.92$. Fig. 2 shows the distribution of $\mathrm{Fe}(\mathrm{III})$ species versus the $\mathrm{pH}$ for $\left[\mathrm{Fe}_{\mathrm{III}}\right]_{\text {tot }}=0.5 \mathrm{mmol} \mathrm{dm}^{-3}$. Under these conditions the dimer contributes mostly in the $\mathrm{pH}$ region 3.0-3.5, but when $\left[\mathrm{Fe}_{\mathrm{III}}\right]_{\text {tot }} \leq 0.1 \mathrm{mmol} \mathrm{dm}^{-3}$ the contribution of $\mathrm{Fe}_{2}(\mathrm{OH})_{2}{ }^{4+}$ can be neglected, while the distribution of the other species remains essentially unaffected.

\section{Sulfur(Iv) in aqueous solution}

When sulfur dioxide reacts with water, $\mathrm{H}_{2} \mathrm{SO}_{3}, \mathrm{HSO}_{3}{ }^{-}$and $\mathrm{SO}_{3}{ }^{2-}$ are formed as products. The sum of these species and their total concentration are designated $\mathrm{S}(\mathrm{Iv})$ and $\left[\mathrm{S}_{\mathrm{IV}}\right]_{\text {tot }}$, respectively. Relative concentrations are determined by the two equilibria:

$$
\begin{gathered}
\mathrm{SO}_{2 \mathrm{aq}}=\mathrm{HSO}_{3}{ }^{-}+\mathrm{H}^{+} \\
\mathrm{HSO}_{3}{ }^{-}=\mathrm{SO}_{3}{ }^{2-}+\mathrm{H}^{+} \\
K_{\mathrm{d} 1}=\left[\mathrm{HSO}_{3}{ }^{-}\right]\left[\mathrm{H}^{+}\right] /\left[\mathrm{SO}_{2 \mathrm{aq}}\right] \\
K_{\mathrm{d} 2}=\left[\mathrm{SO}_{3}{ }^{2-}\right]\left[\mathrm{H}^{+}\right] /\left[\mathrm{HSO}_{3}{ }^{-}\right]
\end{gathered}
$$

Here, $\mathrm{SO}_{2 \mathrm{aq}}$ denotes the sum of physically dissolved $\mathrm{SO}_{2}$ in water and sulfurous acid proper. The former displays a typical feature in the near ultraviolet absorption spectrum, whereas the latter cannot be so identified. Values of the two equilibrium constants at $25{ }^{\circ} \mathrm{C}$ and zero ionic strength (very dilute solution) are: ${ }^{35}{ }^{0} K_{\mathrm{d} 1}=1.39 \times 10^{-2},{ }^{0} K_{\mathrm{d} 2}=6.72 \times 10^{-8}\left(\mathrm{~mol} \mathrm{dm}{ }^{-3}\right)$. In the acidic $\mathrm{pH}$ range considered here the second dissociation process is essentially negligible. Regarding the first dissociation constant a greater number of studies have sought to determine ${ }^{0} K_{\mathrm{d} 1}$, as reviewed by Goldberg and Parker, ${ }^{35}$ whereas the dependence on ionic strength appears to have been of lesser interest. The few reliable data are summarized in Fig. 3, which shows a plot of $\mathrm{p} K_{\mathrm{d} 1}=-\log K_{\mathrm{d} 1}$ as a function of $\mu^{\frac{1}{2}}$ at $25{ }^{\circ} \mathrm{C}$. The only systematic studies are those of Huss and Eckert, ${ }^{36}$ who used spectrophotometry and collected 33 data points at low ionic strength, and of Millero et al., ${ }^{37}$ who employed potentiometric titration with a

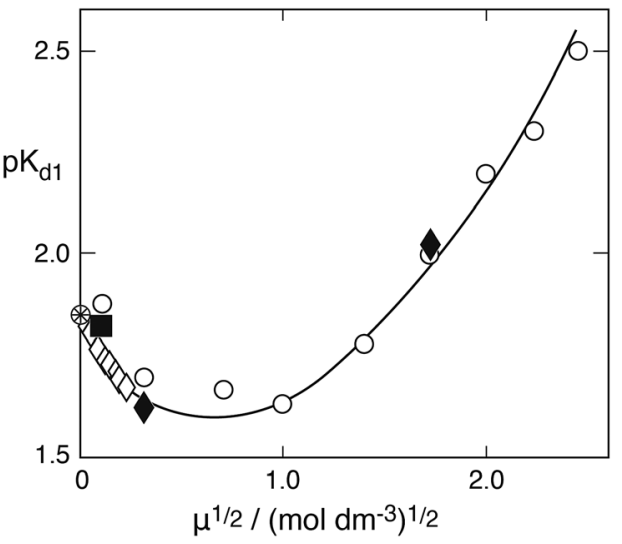

Fig. 3 The $\mathrm{pK}=-\log K_{\mathrm{d} 1}$ of the first dissociation constant of sulfurous acid versus the root of ionic strength: open diamonds (Huss and Eckert ${ }^{36}$ ). filled diamonds (Sekine et al. ${ }^{38}$ ); open points (Millero et al. ${ }^{37}$ ); square (Devèze and Rumpf ${ }^{39}$ ). The solid line was calculated from eqn (4).

focus on high ionic strengths. The two data points of Sekine et al. ${ }^{38}$ were obtained as a byproduct of studying the distribution of S(Iv) between carbon tetrachloride and water by means of iodometry. They agree well with the other data. The single point due to Devèze and Rumpf ${ }^{39}$ is included because these authors also used spectrophotometric measurements. This technique appears to be most reliable. The older data of Frydman et al. ${ }^{40}$ obtained for $\mu=1.0$ and $\mu=3.5 \mathrm{~mol} \mathrm{dm}^{-3}$ by potentiometric titration fall outside the range of the other data by a wide margin and are not shown. The solid line in Fig. 3 represents the best fit to the experimental data by the extended Debye-Hückel equation:

$$
\log K_{\mathrm{d} 1}=\log { }^{0} K_{\mathrm{d} 1}+1.02 \mu^{\frac{1}{2}} /\left(1+1.3 \mu^{\frac{1}{2}}\right)-0.215 \mu
$$

where $\log { }^{0} K_{\mathrm{d} 1}=\log 0.0139=-1.85698$ was kept fixed and the other two parameters were determined by a least square curve fitting program. The factor 1.3 in the denominator of the second term on the right is consistent with the value 1.64, which Huss and Eckert ${ }^{36}$ had adopted by analogy with other 1-1 electrolytes of comparable size. By extrapolating the DebyeHückel equation to $\mu=0$ they had found ${ }^{0} K_{\mathrm{d} 1}=0.0138 \pm 0.0004$, in excellent agreement with ${ }^{0} K_{\mathrm{d} 1}=0.0139 \pm 0.0002$ obtained from conductivity measurements.

\section{Iron(III)-sulfito complexes}

The interaction of S(IV) with Fe(III) leads to the formation of addition complexes that feature absorption spectra in the wavelength region 300-600 $\mathrm{nm}$, partly overlapping the absorption spectra of $\mathrm{FeOH}^{2+}$ and $\mathrm{Fe}(\mathrm{OH})_{2}{ }^{+}$. The complexes are formed rapidly, whereas the subsequent reactions proceed more slowly, so that complex formation is best studied by means of stopped-flow techniques within a millisecond time frame. The early photometric titration experiments of Danilczuk and Swinarski ${ }^{20}$ had indicated the existence of three complexes formed by the stepwise addition of $\mathrm{S}$ (Iv) to $\mathrm{Fe}(\mathrm{III})$ in the $\mathrm{pH}$ range $2-3$, but the results of Conklin and Hoffmann $^{14}$ and of Betterton ${ }^{18}$ subsequently provided evidence for 
the formation of only one complex. The existence of three complexes was ultimately confirmed by Kraft and van Eldik ${ }^{17}$ and by Prinsloo et al., ${ }^{19}$ who employed rapid-scan spectrometry to follow the formation of the complexes as a function of time. The 1:1-complex was found to form very rapidly after mixing the reagents (in the $\mathrm{mmol} \mathrm{dm}{ }^{-3}$ concentration range), the formation of the 1:2-complex was completed within 10-50 ms, and the reaction to form the $1: 3$-complex took up to $200 \mathrm{~ms}$ to be completed. Conklin and Hoffmann ${ }^{14}$ had used a fixed reaction time of $10 \mathrm{~ms}$; Betterton ${ }^{18}$ used a reaction time of $160 \mathrm{~ms}$. The time frame in the latter study would have meant that at least the $1: 1$ and the $1: 2$-complexes were present. This led to uncertainties in the data interpretation. Kraft and van Eldik ${ }^{17}$ had suggested that the 1:2-complex can exist in two isomeric forms, but the data of Prinsloo et al. ${ }^{19}$ did not provide further support for the idea. The following analysis will focus on the results of the last authors because they reported the most comprehensive data set.

Prinsloo et $a l .{ }^{19}$ defined the reaction system in terms of the following equilibria

$$
\begin{gathered}
\mathrm{FeOH}^{2+}+\mathrm{HSO}_{3}{ }^{-}=\mathrm{FeSO}_{3}{ }^{+}+\mathrm{H}_{2} \mathrm{O} \\
\mathrm{FeSO}_{3}{ }^{+}+\mathrm{HSO}_{3}{ }^{-}=\mathrm{Fe}\left(\mathrm{SO}_{3}\right)_{2}{ }^{-}+\mathrm{H}^{+} \\
\mathrm{Fe}\left(\mathrm{SO}_{3}\right)_{2}{ }^{-}+\mathrm{HSO}_{3}{ }^{-}=\mathrm{Fe}\left(\mathrm{SO}_{3}\right)_{3}{ }^{3-}+\mathrm{H}^{+} \\
K_{\mathrm{c} 1}=\left[\mathrm{FeSO}_{3}{ }^{+}\right] /\left[\mathrm{FeOH}^{2+}\right]\left[\mathrm{HSO}_{3}{ }^{-}\right] \\
K_{\mathrm{c} 2}=\left[\mathrm{Fe}\left(\mathrm{SO}_{3}\right)_{2}{ }^{-}\right]\left[\mathrm{H}^{+}\right] /\left[\mathrm{FeSO}_{3}{ }^{+}\right]\left[\mathrm{HSO}_{3}{ }^{-}\right] \\
K_{\mathrm{c} 3}=\left[\mathrm{Fe}\left(\mathrm{SO}_{3}\right)_{3}{ }^{3-}\right]\left[\mathrm{H}^{+}\right] /\left[\mathrm{Fe}\left(\mathrm{SO}_{3}\right)_{2}{ }^{-}\right]\left[\mathrm{HSO}_{3}{ }^{-}\right]
\end{gathered}
$$

The authors did not present equilibrium constants in this form, however. Instead they reported apparent equilibrium constants defined by the equations

$$
\begin{gathered}
K_{\text {c1app }}=\left[\mathrm{FeSO}_{3}{ }^{+}\right] /\left[\mathrm{Fe}_{\mathrm{III}}\right]\left[\mathrm{S}_{\mathrm{IV}}\right] \\
K_{\text {c2app }}=\left[\mathrm{Fe}\left(\mathrm{SO}_{3}\right)_{2}{ }^{-}\right] /\left[\mathrm{FeSO}_{3}{ }^{+}\right]\left[\mathrm{S}_{\mathrm{IV}}\right] \\
K_{\text {c3app }}=\left[\mathrm{Fe}\left(\mathrm{SO}_{3}\right)_{3}{ }^{3-}\right] /\left[\mathrm{Fe}\left(\mathrm{SO}_{3}\right)_{2}{ }^{-}\right] /\left[\mathrm{S}_{\mathrm{IV}}\right]
\end{gathered}
$$

Here, $\left[\mathrm{Fe}_{\mathrm{III}}\right]$ and $\left[\mathrm{S}_{\mathrm{IV}}\right]$ represent the equilibrium concentrations of the sums of the free Fe(III) and S(Iv) species, respectively. The relations between the true equilibrium constants and the apparent ones will be considered further below. Prinsloo et $a{ }^{19}{ }^{19}$ had assumed the 1:2- and 1:3-complexes to be fully dissociated, but this need not be the case. In fact, it will be shown that in the $\mathrm{pH}$ range explored the 1:3-complex occurs primarily in the form $\mathrm{Fe}\left(\mathrm{SO}_{3}\right)_{3} \mathrm{H}^{2-}$. Other authors ${ }^{9,11,12,14,16}$ have considered $\mathrm{Fe}^{3+}$ to be involved in the formation of the 1:1-complex, and they have written reaction (c1) in the form

$$
\begin{gathered}
\mathrm{Fe}^{3+}+\mathrm{HSO}_{3}{ }^{-}=\mathrm{FeSO}_{3}{ }^{+}+\mathrm{H}^{+} \\
K_{\mathrm{c} 1 \mathrm{a}}=\left[\mathrm{FeSO}_{3}{ }^{+}\right]\left[\mathrm{H}^{+}\right] /\left[\mathrm{Fe}^{3+}\right]\left[\mathrm{HSO}_{3}{ }^{-}\right]
\end{gathered}
$$

Yet this reaction is equivalent to the equilibrium (c1) because of the simultaneous equilibrium between $\mathrm{Fe}^{3+}$ and $\mathrm{FeOH}^{2+}$, so that
$K_{\mathrm{c} 1 \mathrm{a}}=K_{\mathrm{c} 1} K_{\mathrm{h} 1}$. The possibility that $\mathrm{SO}_{3}{ }^{2-}$ is the reacting sulfur species rather than $\mathrm{HSO}_{3}{ }^{-}$is rather remote at $\mathrm{pH}<3$. It might become more important when the $\mathrm{pH}$ is raised to values exceeding $\mathrm{pH} 4$.

Prinsloo et al. ${ }^{19}$ as well as other authors ${ }^{14,18}$ have applied the technique of Newton and Arcand ${ }^{41}$ to determine apparent equilibrium constants from the experimental data. The method is based on the equation

$$
A=A_{\infty}-(1 / K)\left(A-A_{0}\right) /\left[\mathrm{S}_{\mathrm{IV}}\right]^{n}
$$

obtained by eliminating $\left[\mathrm{Fe}_{\text {III }}\right] /\left[\mathrm{Fe}_{\text {III }}\right]_{\text {tot }}$ from the fundamental equations that describe the equilibria involved and the total absorbance. It is assumed that only one complex exists and that the equilibrium is fully established. The total concentration of iron is held constant, the concentration $\left[\mathrm{S}_{\mathrm{IV}}\right]$ is varied, and the absorbance $A$ is measured; $A_{0}$ is the absorbance in the absence of S(Iv), $A_{\infty}$ is the absorbance the solution would acquire if all $\mathrm{Fe}(\mathrm{III})$ were incorporated in the complex. The equilibrium constant $K$ is found from the reciprocal of the slope of the line obtained by plotting $A$ vs. $\left(A-A_{0}\right) /\left[\mathrm{S}_{\mathrm{IV}}\right]^{n}$. Newton and Arcand $^{41}$ had introduced the exponent $n=1,2$ or 3 to make allowance for the prompt formation of a complex carrying the corresponding number of ligands. This case does not apply here, because the successive addition of S(Iv) to form complexes with more than one ligand will yield a straight line at low $\left[\mathrm{S}_{\mathrm{IV}}\right]$, when $n=1$, with deviations from linearity at higher $\left[\mathrm{S}_{\mathrm{IV}}\right]$ concentrations when additional complexes with different absorption coefficients are formed. It is important to note that $\left[\mathrm{S}_{\mathrm{IV}}\right]$ represents the actual equilibrium concentration of S(Iv), which is initially not known but can be calculated once $K$ is established. It is customary to set $\left[\mathrm{S}_{\mathrm{IV}}\right] \approx\left[\mathrm{S}_{\mathrm{IV}}\right]_{\text {tot }}$, but this approximation is approached only when $\left[\mathrm{S}_{\text {IV }}\right]_{\text {tot }} \gg\left[\mathrm{Fe}_{\text {III }}\right]_{\text {tot }}$.

Plots of $A$ versus $\left(A-A_{0}\right) /\left[\mathrm{S}_{\mathrm{IV}}\right]_{\text {tot }}$ for the $50-100 \mathrm{~ms}$ time frame reported by Kraft and van Eldik ${ }^{17}$ showed two intercepting linear portions (hockey-stick shape) that were interpreted as being due to the successive formation of $1: 1$ and 1:2-complexes. Betterton ${ }^{18}$ had raised doubts about this interpretation because his data did not show a change in the slope. Prinsloo et al. ${ }^{19}$ then restudied the absorption changes as a function of $\left[\mathrm{S}_{\mathrm{IV}}\right]_{\text {tot }}$, again by means of rapid-scan spectrometry. They largely confirmed the earlier results of Kraft and van Eldik $^{17}$ and derived apparent stability constants for the complexes at $\mathrm{pH} 2.5$ and $\mathrm{pH} 3$, which they found to be essentially independent of wavelength in the region 390-470 $\mathrm{nm}$ (as required). The formation of the 1:1 and $1: 2$-complexes was studied at a reaction time of about $50 \mathrm{~ms}$, that of the 1:3-complex at later times. The values reported at $\mathrm{pH} 2.5$ and $3.0\left(T=25{ }^{\circ} \mathrm{C}, \mu=0.1 \mathrm{~mol} \mathrm{dm}^{-3}\right)$ are: $K_{\text {c1app }}=425 \pm 18$ and $861 \pm 120$, respectively, as well as $K_{\text {c2app }}=231 \pm 16$ and $604 \pm 52$, $K_{\text {c3app }}=158 \pm 18$ and $190 \pm 25$ (units: $\mathrm{mol}, \mathrm{dm}^{3}$ ).

Corrections are still required because the equilibrium concentrations $\left[\mathrm{S}_{\mathrm{IV}}\right]<\left[\mathrm{S}_{\mathrm{IV}}\right]_{\text {tot }}$. At short reaction times, when only the $1: 1$ and 1:2-complexes are present, the relevant mass balance equations are

$$
\left[\mathrm{S}_{\mathrm{IV}}\right]_{\text {tot }}=\left[\mathrm{S}_{\mathrm{IV}}\right]+K_{\mathrm{c} 1 \mathrm{app}}\left[\mathrm{Fe}_{\mathrm{III}}\right]\left[\mathrm{S}_{\mathrm{IV}}\right]+2 K_{\mathrm{c} 1 \mathrm{app}} K_{\mathrm{c} 2 \mathrm{app}}\left[\mathrm{Fe}_{\mathrm{III}}\right]\left[\mathrm{S}_{\mathrm{IV}}\right]^{2}
$$




$$
\left[\mathrm{Fe}_{\text {IIII }}\right]_{\text {tot }}=\left[\mathrm{Fe}_{\text {III }}\right]\left(1+K_{\text {c1app }}\left[\mathrm{S}_{\mathrm{IV}}\right]+K_{\text {c1app }} K_{\text {c2app }}\left[\mathrm{S}_{\mathrm{IV}}\right]^{2}\right)
$$

The elimination of $\left[\mathrm{Fe}_{\mathrm{III}}\right]$ leads to a cubic equation for [ $\left.\mathrm{S}_{\mathrm{IV}}\right]$, which is conveniently solved by iteration techniques. Prinsloo et al. ${ }^{19}$ have applied $\left[\mathrm{Fe}_{\mathrm{III}}\right]_{\text {tot }}=1 \mathrm{mmol} \mathrm{dm}^{-3}$ and $\left[\mathrm{S}_{\mathrm{IV}}\right]_{\text {tot }}=$ $1-20 \mathrm{mmol} \mathrm{dm}^{-3}$. Under these conditions it is found that at low concentrations of $\left[\mathrm{S}_{\mathrm{IV}}\right]_{\text {tot }}$ the ratio $\left[\mathrm{S}_{\mathrm{IV}}\right] /\left[\mathrm{S}_{\mathrm{IV}}\right]_{\text {tot }} \approx 0.6$ at $\mathrm{pH} 2.5$, and $\sim 0.5$ at $\mathrm{pH}$ 3. At higher concentrations $\left[\mathrm{S}_{\mathrm{IV}}\right] /\left[\mathrm{S}_{\mathrm{IV}}\right]_{\text {tot }}$ approaches unity. The ratios depend little on the exact choice of $K_{\text {c1app }}$ and $K_{\text {c2app. }}$. It will be clear that corrections are required when the value of the first equilibrium constant is sought, whereas the equilibrium constants of the two higher complexes are much less thus affected. Estimates for the corrected $K_{\text {c1app }}$ values may be obtained by applying the calculated correction factors directly to the reported $K_{\text {c1app }}$. This results in values of $773 \pm 33$ at pH 2.5 and $1722 \pm 240$ at $\mathrm{pH} 3$.

Prinsloo et al. ${ }^{19}$ also presented (in their Fig. 2) measured absorbances $A$ at $\lambda=390 \mathrm{~nm}$ as a function of $\left[\mathrm{S}_{\mathrm{IV}}\right]_{\text {tot }}$ that can be used together with estimated values of $A_{0}$ to prepare new Newton-Arcand plots based on the calculated $\left[\mathrm{S}_{\mathrm{IV}}\right]$ concentrations. The upper part of Fig. 4 shows the measured absorbance curves,$^{19}$ while the lower part presents the corresponding Newton-Arcand plots at pH 2 and $\mathrm{pH}$ 2.5. Both demonstrate the hockey-stick shape, which indicates the increasing influence of the 1:2-complex when $\left[\mathrm{S}_{\mathrm{IV}}\right]_{\text {tot }}$ is raised. The $K_{\text {c1app }}$ values obtained from the initial slopes are $320 \pm 26$ at pH 2 and $787 \pm 216$ at $\mathrm{pH}$ 2.5. Data for $\mathrm{pH} 3$ are not shown, because the number of data points defining the initial rise of absorbance is
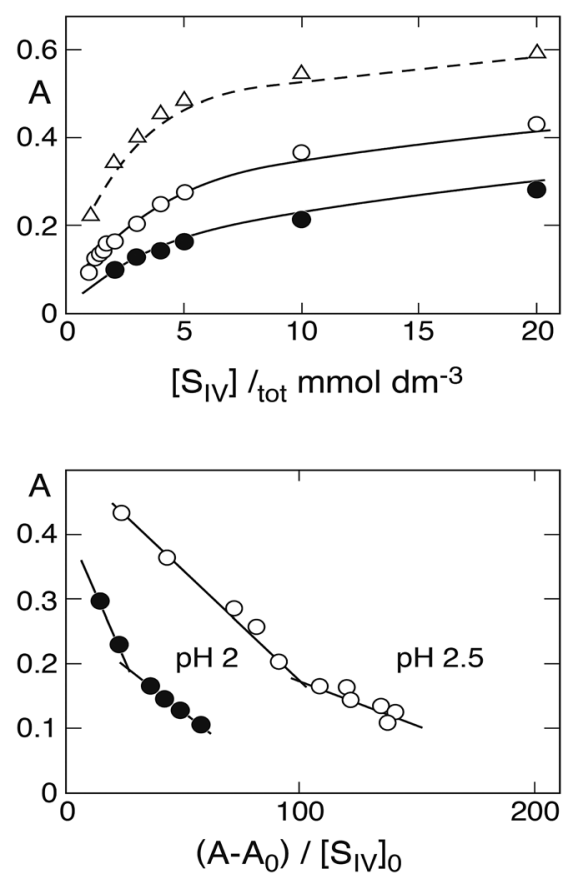

Fig. 4 Top: Rise of absorbance at $390 \mathrm{~nm}$ with increasing S(Iv) concentration (Prinsloo et al. ${ }^{19}$ ), points $\mathrm{pH} 2$, circles $\mathrm{pH} 2.5$, triangles $\mathrm{pH} 3$. Lines are calculated in the first two cases with $\varepsilon\left(\mathrm{FeSO}_{3}{ }^{+}\right)=270, \varepsilon\left(\mathrm{Fe}\left(\mathrm{SO}_{3}\right)_{2}{ }^{-}\right)=$ $400, \varepsilon\left(\mathrm{Fe}\left(\mathrm{SO}_{3}\right)_{3} \mathrm{H}^{2-}\right)=450\left(\mathrm{dm}^{3} \mathrm{~mol}^{-1} \mathrm{~cm}^{-1}\right)$; different values are needed to reproduce the absorbance curve at $\mathrm{pH} 3$ (broken line, see text). Bottom: Newton-Arcand plots of the absorbance data at $\mathrm{pH} 2$ and 2.5 . insufficient to allow a reasonably reliable evaluation. An estimate obtained from the first two points is $K_{\mathrm{c} 1 \mathrm{app}} \approx 2230$, which is much higher than, and clearly inconsistent with, the approximate value $1722 \pm 240$ obtained above. However, the value reported by Prinsloo et al. ${ }^{19}$ at $\lambda=390 \mathrm{~nm}, K_{\mathrm{c} 1 \mathrm{app}}=916 \pm 113$, is also higher than the average obtained from data at all wavelengths. The values for $K_{\mathrm{c} 2 a p p}$ obtained at $\mathrm{pH} 2.5$ and $\mathrm{pH}$ 3 were only slightly different from those given above, ${ }^{19}$ the differences falling within the range of the experimental error.

In order to determine the true stability constants from the apparent ones, reference is made to the definitions of the equilibrium constants $K_{\mathrm{c} 1}-K_{\mathrm{c} 3}$ and $K_{\mathrm{c} 1 \mathrm{app}}-K_{\mathrm{c} 3 \mathrm{app}}$. Thus, one finds for the 1:1-complex

$$
\begin{aligned}
{\left[\mathrm{FeSO}_{3}{ }^{+}\right]=} & K_{\mathrm{c} 1}\left[\mathrm{FeOH}^{2+}\right]\left[\mathrm{HSO}_{3}{ }^{-}\right]=K_{\mathrm{c1app}}\left[\mathrm{Fe}_{\mathrm{III}}\right]\left[\mathrm{S}_{\mathrm{IV}}\right]=K_{\mathrm{c1app}}\left(\left[\mathrm{Fe}^{3+}\right]\right. \\
& \left.+\left[\mathrm{FeOH}^{2+}\right]\right)\left(\left[\mathrm{SO}_{2 \mathrm{aq}}\right]+\left[\mathrm{HSO}_{3}{ }^{-}\right]+\left[\mathrm{SO}_{3}{ }^{2-}\right]\right)
\end{aligned}
$$

From the equilibria involving the reactants and the associated equilibrium constants $K_{\mathrm{h} 1}=2.87 \times 10^{-3} ; K_{\mathrm{d} 1}=2.24 \times 10^{-2}$; $K_{\mathrm{d} 2}=1.5 \times 10^{-7}$ (at $\mu=0.1$ and $25^{\circ} \mathrm{C}$ ) it follows that

$$
K_{\mathrm{c} 1}=K_{\mathrm{c} 1 \text { app }}\left(1+\left[\mathrm{H}^{+}\right] / K_{\mathrm{h} 1}\right)\left(1+\left[\mathrm{H}^{+}\right] / K_{\mathrm{d} 1}+K_{\mathrm{d} 2} /\left[\mathrm{H}^{+}\right]\right)
$$

The individual values of $K_{\mathrm{c} 1}$ calculated from the apparent stability constants derived at $\mathrm{pH} 2$ and pH 2.5 are $2075 \pm 167$ and $1889 \pm 518 \mathrm{dm}^{3} \mathrm{~mol}^{-1}$. The average is $1982 \pm 518 \mathrm{dm}^{3} \mathrm{~mol}^{-1}$, where the statistical uncertainty is that of the reported measurements. The value at $\mathrm{pH} 3$ derived from the corrected overall average, $1722 \pm 240$, would be $K_{\mathrm{c} 1}=2426 \pm 338$, which is at the upper end of the error range. The value will not be used, because at $\mathrm{pH} 3$ other iron-sulfito complexes may contribute to the observed absorbances (vide infra). The corrected value estimated from the overall average given by Prinsloo et al. ${ }^{19}$ at $\mathrm{pH} 2.5$ is $K_{\mathrm{c} 1}=1855 \pm 80$, which agrees well with that derived here from the data at $390 \mathrm{~nm}$.

The equilibrium constant for the formation of the $1: 2$ complex is,

$$
K_{\text {c2 }}=K_{\text {c2app }}\left[\mathrm{H}^{+}\right]\left(1+\left[\mathrm{H}^{+}\right] / K_{\mathrm{d} 1}+K_{\mathrm{d} 2} /\left[\mathrm{H}^{+}\right]\right)=0.733 \pm 0.102
$$

This value is the average of the individual results $0.834 \pm$ 0.058 at pH 2.5 and $0.631 \pm 0.054$ at pH 3. Here, the statistical uncertainty is that of the averaging process. The experimental error range is larger.

Finally, the equilibrium between the $1: 2$ - and $1: 3$-complexes is considered. In this case, the observed $K_{\text {c3app }}$ values show only a slight dependence on $\mathrm{pH}$, indicating that the 1:3-complex remains nearly fully protonated in the (admittedly narrow) $\mathrm{pH}$ range covered. Accordingly, reaction (c3) should be written

$$
\begin{gathered}
\mathrm{Fe}\left(\mathrm{SO}_{3}\right)_{2}{ }^{-}+\mathrm{HSO}_{3}{ }^{-}=\mathrm{Fe}\left(\mathrm{SO}_{3}\right)_{3} \mathrm{H}^{2-} \\
K_{\mathrm{c} 3 \mathrm{a}}=\left[\mathrm{Fe}\left(\mathrm{SO}_{3}\right)_{3} \mathrm{H}^{2-}\right] /\left[\mathrm{Fe}\left(\mathrm{SO}_{3}\right)_{2}{ }^{-}\right]\left[\mathrm{HSO}_{3}{ }^{-}\right]
\end{gathered}
$$

The corresponding equilibrium constant is

$$
K_{\text {c3a }}=K_{\text {c3app }}\left(1+\left[\mathrm{H}^{+}\right] / K_{\mathrm{d} 1}+K_{\mathrm{d} 2} /\left[\mathrm{H}^{+}\right]\right)=189 \pm 9 \mathrm{dm}^{3} \mathrm{~mol}^{-1}
$$


The value on the right is the average of the two results $180 \pm$ 21 and $198 \pm 26$ obtained at $\mathrm{pH} 2.5$ and $\mathrm{pH} 3$, respectively. Here, the experimental error range is again greater than the statistical uncertainty of the averaging process.

It must be kept in mind that these results refer to an ionic strength $\mu=0.1$. The Debye-Hückel theory predicts $\log K_{\mathrm{c} 1}=$ $\log { }^{0} K_{\mathrm{c} 1}-2.04 \mu^{\frac{1}{2}} /\left(1+a \mu^{\frac{1}{2}}\right), \log K_{\mathrm{c} 2} \approx \log { }^{0} K_{\mathrm{c} 2}$ (no significant ionic strength dependence), and $\log K_{\mathrm{c} 3 \mathrm{a}}=\log { }^{0} K_{\mathrm{c} 3 \mathrm{a}}+1.02 \mu^{\frac{1}{2}} /$ $\left(1+\beta \mu^{\frac{1}{2}}\right)$. The factors $a$ and $\beta$ in the denominators of the second terms must be estimated. Regarding the equilibrium constant $K_{\mathrm{c} 1}$ Lente and Fabian ${ }^{16}$ have found $K_{\mathrm{c} 1 \mathrm{a}}=K_{\mathrm{c} 1} K_{\mathrm{h} 1}=1.35 \pm 0.15$ at $\mu=1.0 \mathrm{~mol} \mathrm{dm}^{-3}$; which is equivalent to $K_{\mathrm{c} 1}=825 \pm 92$ at this ionic strength. The corresponding value of $a$ in the extended Debye-Hückel equation would be $a \approx 1.5$. The value of $K_{\mathrm{c} 3 \mathrm{a}}$ increases with increasing ionic strength, but the effect is not very pronounced, and it is neglected in calculating equilibrium distributions of the $\mathrm{Fe}(\mathrm{III})$ species.

In order to compare the above results with those obtained by Conklin and Hoffmann ${ }^{14}$ and by Betterton ${ }^{18}$ it is necessary to calculate the relative distribution among the three complexes at the reaction times used by these authors. Rate coefficients for the formation of the complexes that are required for the calculations will be discussed in the next section. Here, only the results of such calculations are used. ${ }^{42}$ The experimental conditions applied by Conklin and Hoffmann ${ }^{14}$ were: $\mathrm{pH}$ 2.1,

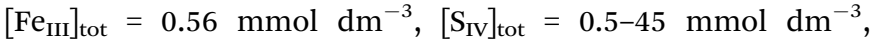
$\mu=0.4 \mathrm{~mol} \mathrm{dm}^{-3}, \Delta t=10 \mathrm{~ms}$. The calculated distribution of the complexes under these conditions shows that the first complex dominates only at very low S(Iv) concentrations where the scatter of the measured absorbances would have obscured the initial slope determined by $K_{\text {c1app. }}$ The bulk of the data refer to the second complex. In this region the contribution of the first complex remains nearly constant and the contribution of the third complex can be ignored. Measurements made at two wavelengths (350 and $450 \mathrm{~nm}$ ) gave apparent $K$-values of 57.2 and 76.4, respectively, with an average of $K_{\text {c2app }}=66.8 \pm$ $10.4 \mathrm{dm}^{3} \mathrm{~mol}^{-1}$. When the correction factor of eqn (8) is applied, one obtains the true equilibrium constant $K_{\mathrm{c} 2}=$ $0.694 \pm 0.11$, which is in excellent agreement with the value calculated above from the data of Prinsloo et al. ${ }^{19}$ Thus, the three values can be combined to derive an overall average $K_{\mathrm{c} 2}=0.72 \pm 0.08$.

Betterton $^{18}$ has explored the change with $\mathrm{pH}$ of the apparent equilibrium constant under experimental conditions quite similar to those of Conklin and Hoffmann. ${ }^{14}$ The major difference was the longer reaction time $(\Delta t=160 \mathrm{~ms})$ spent between mixing the reagents and observing the products in the optical cuvette. The measured $K_{\text {app }}$ was found to increase as the $\mathrm{pH}$ was raised from 1 to 3 whence a plateau was reached. This observation is in accord with the notion that the formation of the complexes proceeds via $\mathrm{FeOH}^{2+}$ and $\mathrm{HSO}_{3}{ }^{-}$as the active reactants, since the concentrations of both species increase with increasing $\mathrm{pH}$. The calculated time dependence for the formation of the complexes indicates that at $\mathrm{pH} 1$ where the concentrations of the reactants are small, the 1 :1-complex is still dominant after $160 \mathrm{~ms}$ reaction time, even at high S(Iv) concentrations. This condition applies also at $\mathrm{pH} 1.25$ over most of the $\left[\mathrm{S}_{\mathrm{IV}}\right]$ concentration range. Thus, the $K$-values reported by Betterton ${ }^{18}$ at low $\mathrm{pH}$ can be identified with $K_{\text {c1app}}$. At pH $1\left(\left[\mathrm{Fe}_{\mathrm{III}}\right]_{\mathrm{tot}}=1.25 \times 10^{-4} \mathrm{~mol} \mathrm{dm}{ }^{-3}, \mu=0.5\right)$ the average of the reported $K$-values is $K_{\text {c1app }}=8.3 \pm 3.7$ ( 3 wavelengths), and at pH $1.25\left(\left[\mathrm{Fe}_{\mathrm{III}}\right]_{\text {tot }}=5.0 \times 10^{-4} \mathrm{~mol} \mathrm{dm}^{-3}, \mu=0.2\right)$ the average is $K_{\text {c1app }}=11.4 \pm 1.6$ ( 6 wavelengths). Calculations for these experimental conditions show that $\left[\mathrm{S}_{\mathrm{IV}}\right] \approx\left[\mathrm{S}_{\mathrm{IV}}\right]_{\text {tot }}$ so that corrections for $\left[\mathrm{S}_{\mathrm{IV}}\right]$ are not required. The true equilibrium constants, defined by eqn (7a), are then calculated to be $K_{\mathrm{c} 1}=2143 \pm 952 \mathrm{dm}^{-3} \mathrm{~mol}^{-1}$ at $\mathrm{pH} 1, K_{\mathrm{c} 1}=913 \pm 128 \mathrm{dm}^{-3} \mathrm{~mol}^{-1}$ at $\mathrm{pH} 1.25$. These values must be corrected for the ionic strength effect in order that they can be compared with the results of Prinsloo et al. ${ }^{19}$ which were obtained at $\mu=0.1$. The corrected $K_{\mathrm{c} 1}$ values are estimated to be $3781 \pm 1678$ and $1151 \pm 161 \mathrm{dm}^{3} \mathrm{~mol}^{-1}$ at $\mathrm{pH} 1$ and 1.25 , respectively. The values bracket that derived from the data of Prinsloo et al. ${ }^{19}$ but it is not obvious, why they diverge so much from each other.

The $K_{\text {app }}$-values reported by Betterton ${ }^{18}$ at $\mathrm{pH} 2$ compare quite favorably with those of Conklin and Hoffmann ${ }^{14}$ at pH 2.1. Therefore, the 1:2-complex appears to be primarily involved. Rather similar results were obtained with $\left[\mathrm{Fe}_{\mathrm{III}}\right]_{\text {tot }}=$ $2.5 \times 10^{-4}$ and $5.0 \times 10^{-4} \mathrm{~mol} \mathrm{dm}{ }^{-3}$. The average of 8 individual values obtained at 5 different wavelengths is $82.0 \pm 11.2$. The corresponding true equilibrium constant calculated with the help of eqn (8) is $K_{\mathrm{c} 2}=1.15 \pm 0.16$. This result is higher than that derived above from the data of the other authors, ${ }^{14,19}$ but the calculated time dependence for complex formation shows that at the longer reaction time used by Betterton ${ }^{18}$ the contribution of the 1:3-complex cannot be fully ignored. At concentrations $\left[\mathrm{S}_{\mathrm{IV}}\right]_{\text {tot }}$ $\geq 10 \mathrm{mmol} \mathrm{dm}{ }^{-3}$ the 1:3-complex becomes the dominant species, requiring appropriate corrections. The overall conclusion is that the results obtained by Betterton ${ }^{18}$ for this $\mathrm{pH}$ regime agree reasonably well with the other data discussed above. In the $\mathrm{pH}$ range $2-3$, however, all three complexes are simultaneously present at similar concentrations, which makes it difficult to interpret the Newton-Arcand plots in a simple manner even if straight lines are observed. Note that nearly straight lines would be obtained if the 1:2- and 1:3-complexes featured absorption coefficients of similar magnitude. From the preceding discussion it will be clear that much of the difficulty experienced in disentangling the three equilibria from simple absorbance measurements is due to the complexity of the system and the necessity of finding suitable experimental conditions for the task.

The stability constants derived above for the $\mathrm{Fe}(\mathrm{III})-\mathrm{S}$ (Iv) complexes may be summarized as follows: $K_{\mathrm{c} 1}=1982 \pm$ $518 \mathrm{dm}^{3} \mathrm{~mol}^{-1}(\mu=0.1), K_{\mathrm{c} 1}=825 \pm 92 \mathrm{dm}^{3} \mathrm{~mol}^{-1}(\mu=1.0)$, $K_{\mathrm{c} 2}=0.72 \pm 0.08(\mu=0.1), K_{\mathrm{c} 3 \mathrm{a}}=189 \pm 9 \mathrm{dm}^{3} \mathrm{~mol}^{-1}(\mu=0.1)$. These values will be employed further below when discussing the slow reaction following the formation of $\mathrm{Fe}(\mathrm{III})-\mathrm{S}$ (IV) complexes.

\section{Rates of formation of iron-sulfito- complexes}

Kraft and van Eldik $^{17}$ presented apparent rate coefficients for the formation of the second and third complexes. The formation of the first complex was too fast to be studied by stopped-flow 
spectrometry $\left(k_{\mathrm{c} 1 \mathrm{f}}>10^{3} \mathrm{~s}^{-1}\right)$. Betterton ${ }^{18}$ used a pulseaccelerated flow technique to estimate the second order rate constant for the formation of the 1:1-complex. He reported $k_{\mathrm{c} 1 \mathrm{f}}=4.0 \times 10^{6} \mathrm{dm}^{3} \mathrm{~mol}^{-1} \mathrm{~s}^{-1}$ at $\mathrm{pH} 2$. This result when combined with the equilibrium constant derived above suggests $k_{\mathrm{c} 1 \mathrm{f}}=4.0 \times 10^{6}, k_{\mathrm{c} 1 \mathrm{r}}=2.08 \times 10^{3}$ for the rate coefficients of the forward and reverse reactions. Kraft and van Eldik ${ }^{17}$ used a stopped-flow instrument with a short mixing time $(\sim 0.2 \mathrm{~ms})$ to measure rate constants for the formation of the complex appearing within the 1-10 ms time frame (denoted step I).

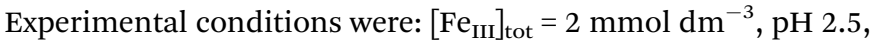
$\mu=0.1$, and $\left[\mathrm{S}_{\mathrm{IV}}\right]_{\text {tot }}$ was varied between 10 and $60 \mathrm{mmol} \mathrm{dm}^{-3}$. The high concentrations of S(Iv) combined with the time frame used make it fairly certain that the 1 :2-complex was observed. The rate constant was found to vary linearly with $\left[\mathrm{S}_{\mathrm{IV}}\right]_{\text {tot }}$ (their Fig. 6a). From the slope of the straight line one obtains $k_{\text {c2app }}=$ $5.2 \times 10^{3} \mathrm{dm}^{3} \mathrm{~mol}^{-1} \mathrm{~s}^{-1}$. A correction is needed to take into account that the reactive species is $\mathrm{HSO}_{3}{ }^{-}$. The appropriate correction factor $\left(1+\left[\mathrm{H}^{+}\right] / K_{\mathrm{d} 1}+K_{\mathrm{d} 2} /\left[\mathrm{H}^{+}\right]\right)$leads to $k_{\mathrm{c} 2 \mathrm{f}}=5.9 \times$ $10^{3} \mathrm{dm}^{3} \mathrm{~mol}^{-1} \mathrm{~s}^{-1}$. The rate coefficient for the reverse reaction step is calculated to be $k_{\mathrm{c} 2 \mathrm{r}}=k_{\mathrm{c} 2 \mathrm{f}} / K_{\mathrm{c} 2}=8.24 \times 10^{3} \mathrm{dm}^{3} \mathrm{~mol}^{-1} \mathrm{~s}^{-1}$. The formation of the $1: 3$-complex proceeds subsequent to that of the 1:2-complex. Kraft and van Eldik ${ }^{17}$ found that it can be conveniently followed by means of stopped-flow spectrometry within the time frame 50-200 ms (step II). The experimental

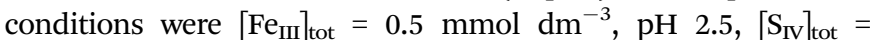
5-50 mmol dm${ }^{-3}, \mu=0.1$. Rate coefficients were measured as a function of $\left[\mathrm{S}_{\mathrm{IV}}\right]$ at two wavelengths (390 and $450 \mathrm{~nm}$ ). From the slopes of the straight lines obtained in plots of $k_{\mathrm{c} 3 a p p} v s$. [ $\left.\mathrm{S}_{\mathrm{IV}}\right]$ (their Fig. 8 and 9) one obtains $k_{\text {c3app }}=3.3 \times 10^{3} \mathrm{dm}^{3} \mathrm{~mol}^{-1} \mathrm{~s}^{-1}$. The correction needed to take into account that $\mathrm{HSO}_{3}{ }^{-}$is the true reactant raises the value to $k_{\text {c3af }}=3.8 \times 10^{3} \mathrm{dm}^{3} \mathrm{~mol}^{-1} \mathrm{~s}^{-1}$. The corresponding rate coefficient for the reverse reaction step then is $k_{\mathrm{c} 3 \mathrm{ar}}=k_{\mathrm{c} 3 \mathrm{af}} / K_{\mathrm{c} 3 \mathrm{a}}=20.1 \mathrm{~s}^{-1}$.

These data were used to explore the successive formation of the three complexes and the overall development of the system as a function of time. Fig. 5 shows, as an example, the development

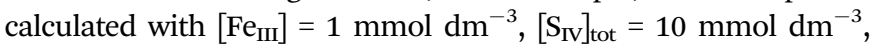
pH 2.5. The equilibrium between $\mathrm{FeOH}^{2+}$ and the $1: 1$-complex is reached at times shorter than $1 \mathrm{~ms}$. Full equilibrium between all three complexes is reached about $250 \mathrm{~ms}$ after mixing the reagents.

\section{Absorption coefficients}

As a consistency check the rate coefficients and equilibrium constants derived above may be used to calculate absorbance curves for comparison with the experimental results reported at $\lambda=390 \mathrm{~nm}^{19}$ as a function of $\left[\mathrm{S}_{\mathrm{IV}}\right]_{\text {tot }}$ at three different $\mathrm{pH}$ (2.0, 2.5 and 3.0). The reaction time was 50-100 $\mathrm{ms},\left[\mathrm{Fe}_{\mathrm{III}}\right]_{\text {tot }}=$ $1 \mathrm{mmol} \mathrm{dm}^{-3}(\mu=0.1)$. Molar absorption coefficients required for the calculation can in principle be estimated from the Newton-Arcand plots by extrapolating the observed straight lines back to the ordinate, where $A \rightarrow A_{\infty}$. The method can also be applied when two complexes are successively formed,

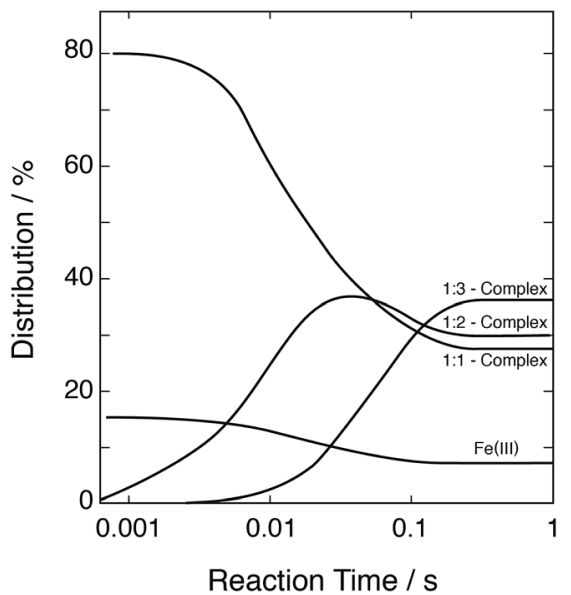

Fig. 5 Evolution with time of the distribution of the Fe(III)-S(IV) complexes; initial concentrations: $\left[\mathrm{Fe}_{\mid I I}\right]_{\text {tot }}=1 \mathrm{mmol} \mathrm{dm}{ }^{-3},\left[\mathrm{~S}_{\mathrm{IV}}\right]_{\mathrm{tot}}=10 \mathrm{mmol} \mathrm{dm}^{-3}$, $\mathrm{pH} 2.5$.

provided the straight lines observed are clearly separated. This implies that the absorption coefficients of the two complexes have distinctly different values. Prinsloo et al. ${ }^{19}$ have estimated absorption coefficients (their Table 1), but these refer to $\mathrm{Fe}(\mathrm{III})$ and S(Iv) as reactants and should be considered order of magnitude values. An alternative method is to calculate the relative distributions of the individual complexes under the experimental conditions applied and adjust the individual values of the absorption coefficients until the observed absorbance curve is reproduced. As absorption coefficients are constants, the values should not change when the $\mathrm{pH}$ is varied.

Fig. 4 includes calculated absorbance curves for comparison with the measurements. The absorption coefficient of $\mathrm{Fe}^{3+}$ at $390 \mathrm{~nm}$ is essentially zero, and that of the first hydrolysis product is $\varepsilon\left(\mathrm{FeOH}^{2+}\right) \approx 60 \mathrm{dm}^{3} \mathrm{~mol}^{-1} \mathrm{~cm}^{-1} \cdot{ }^{19,28,33}$ Absorption coefficients that were found to provide good agreement between calculated and observed absorbances at both $\mathrm{pH} 2.0$ and 2.5 are $\varepsilon\left(\mathrm{FeSO}_{3}{ }^{+}\right)=270, \varepsilon\left(\mathrm{Fe}\left(\mathrm{SO}_{3}\right)_{2}{ }^{-}\right)=400, \varepsilon\left(\mathrm{Fe}\left(\mathrm{SO}_{3}\right)_{3} \mathrm{H}^{2-}\right)=$ $450\left(\mathrm{dm}^{3} \mathrm{~mol}^{-1} \mathrm{~cm}^{-1}\right)$. Fig. 4 indicates the extent of the agreement. These absorption coefficients, however, cannot reproduce the absorbance curve at $\mathrm{pH}$ 3.0. To obtain a good fit in this case would require $\varepsilon\left(\mathrm{FeSO}_{3}{ }^{+}\right)=500, \varepsilon\left(\mathrm{Fe}\left(\mathrm{SO}_{3}\right)_{2}{ }^{-}\right)=400$, $\varepsilon\left(\mathrm{Fe}\left(\mathrm{SO}_{3}\right)_{3} \mathrm{H}^{2-}\right)=650\left(\mathrm{dm}^{3} \mathrm{~mol}^{-1} \mathrm{~cm}^{-1}\right)$. Fig. 4 shows the result by the broken line. The discrepancy suggests that at $\mathrm{pH} 3$ the reaction mixture contains one or more additional absorbers.

At $\mathrm{pH} 3$ one enters into a $\mathrm{pH}$ regime where the $\mathrm{Fe}(\mathrm{III})$ hydrolysis product $\mathrm{Fe}(\mathrm{OH})_{2}{ }^{+}$increases in importance, and the dimer $\mathrm{Fe}_{2}(\mathrm{OH})_{2}{ }^{4+}$ must also be taken into account (see Fig. 2). The distribution of $\mathrm{Fe}(\mathrm{III})$ species at $\mathrm{pH} 3$ with $\left[\mathrm{Fe}_{\text {III }}\right]_{\mathrm{tot}}=1 \mathrm{mmol}$ $\mathrm{dm}^{-3}$ is $\left[\mathrm{Fe}^{3+}\right]=22 \%,\left[\mathrm{FeOH}^{2+}\right]=64 \%,\left[\mathrm{Fe}(\mathrm{OH})_{2}{ }^{+}\right]=7.5 \%$, and $\left[\mathrm{Fe}_{2}(\mathrm{OH})_{2}{ }^{4+}\right]=6.5 \%$. The dimer has been shown by Lente and Fabian ${ }^{16}$ to react with $\mathrm{HSO}_{3}{ }^{-}$to form the $\mathrm{Fe}_{2} \mathrm{OHSO}_{3}{ }^{3+}$ complex; $\mathrm{Fe}(\mathrm{OH})_{2}{ }^{+}$is also expected to react with $\mathrm{HSO}_{3}{ }^{-}$; both $\mathrm{FeOHSO}_{3}$ and $\mathrm{FeSO}_{3}{ }^{+}$are possible products. The equilibrium constant between $\mathrm{Fe}_{2} \mathrm{OHSO}_{3}{ }^{3+}$ and its precursors is $K_{21}=2344,{ }^{16}$ and the rate of formation is rapid. The absorption coefficient of the complex at $\lambda=450 \mathrm{~nm}$ is $\varepsilon\left(\mathrm{Fe}_{2} \mathrm{OHSO}_{3}{ }^{3+}\right)=500 \mathrm{dm}^{3} \mathrm{~mol}^{-1} \mathrm{~cm}^{-1}$; 
at $390 \mathrm{~nm}$ it would be at least twice as large. When this complex is taken into account, the initial rise of the calculated absorbance curve, setting $\varepsilon\left(\mathrm{FeSO}_{3}{ }^{+}\right)=270 \mathrm{dm}^{3} \mathrm{~mol}^{-1} \mathrm{~cm}^{-1}$, agrees much better with that observed experimentally, ${ }^{19}$ but it does not entirely alleviate the discrepancy between calculated and observed absorbances at high concentrations of S(Iv). The necessity of taking into account additional equilibria demonstrates the growing complexity of the system. Further studies are needed to identify the additional reactions active in the region $\mathrm{pH} \geq 3$. One of the consequences of the presence of other iron-sulfito complexes and their contribution to the total absorbance is their interference in the determination of $K_{\text {c1app }}$ by means of Newton-Arcand plots. These additional complexes presumably are responsible for the comparably high value of $K_{\mathrm{c} 1}$ obtained at $\mathrm{pH} 3$ from the measured absorbances at $\lambda=390 \mathrm{~nm}$.

\section{Reactions following the formation of iron-sulfito complexes}

The ultimate products resulting from the interaction of $\mathrm{Fe}(\mathrm{III})$ with S(Iv) in the absence of oxygen are $\mathrm{Fe}(\mathrm{II})$, sulfate and dithionate. The majority of studies of the slow reaction were carried out at $\mathrm{pH} \sim 1$ (and $\mu \approx 1 \mathrm{~mol} \mathrm{dm}^{-3}$ ) where $\mathrm{FeSO}_{3}{ }^{+}$is the dominant iron-sulfito complex. Kuzminykh and Bomshtein ${ }^{43}$ and Higginson and Marshall ${ }^{9}$ both found that the yield of dithionate increases with rising $\left[\mathrm{S}_{\mathrm{IV}}\right] /\left[\mathrm{Fe}_{\mathrm{III}}\right]$ ratio, and that the addition of $\mathrm{Fe}(\mathrm{II})$ causes the rate of the reaction to decline, whereas the addition of $\mathrm{Cu}(\mathrm{II})$ accelerates it. By analogy with other one-equivalent oxidizing reagents, Higginson and Marshall ${ }^{9}$ proposed a simple reaction mechanism involving the $\mathrm{SO}_{3}{ }^{-}$radical as an intermediate. In this mechanism the reaction of $\mathrm{SO}_{3}{ }^{-}$with $\mathrm{Fe}^{2+}$ reverses the decomposition of $\mathrm{FeSO}_{3}{ }^{+}$, thereby reducing the overall reaction rate, whereas the reaction with $\mathrm{Fe}^{3+}$ scavenges $\mathrm{SO}_{3}{ }^{-}$radicals and promotes the decomposition of $\mathrm{FeSO}_{3}{ }^{+}$. The effect of $\mathrm{Cu}^{2+}$ is to catalyze the last process. We note in passing that $\mathrm{Cu}(\mathrm{II})$ also interacts with $\mathrm{S}$ (Iv) to form an addition complex, which is prone to decompose. ${ }^{44}$ In acidic solutions, however, the reaction is slow (in contrast to alkaline solutions); hence its neglect is justified.

Pollard et $a .^{10}$ first demonstrated that the rate of the reaction between Fe(III) and S(IV) (without additives) decreases with time due to the rise of the concentration of $\mathrm{Fe}$ (II) formed as a product. They also found the rate of dithionate production to approach one half of that for the consumption of Fe(III) when $[\mathrm{S}(\mathrm{IV})]_{0} /[\mathrm{Fe}(\mathrm{III})]_{0}>0.5$; but most importantly, they found that the reaction $2 \mathrm{SO}_{3}{ }^{-} \rightarrow \mathrm{S}_{2} \mathrm{O}_{6}{ }^{2-}$, which Higginson and Marshall had assumed to be the source of dithionate, is incompatible with the observed dependence of the rate of dithionate formation on the initial reactant concentrations. Accordingly another reaction must serve as a source of dithionate. In the present study it was found that the reaction $\mathrm{SO}_{3}{ }^{-}+\mathrm{FeSO}_{3}{ }^{+} \rightarrow$ $\mathrm{Fe}^{2+}+\mathrm{S}_{2} \mathrm{O}_{6}{ }^{2-}$ agrees with most of the experimental data. The reaction $2 \mathrm{SO}_{3}{ }^{-} \rightarrow \mathrm{S}_{2} \mathrm{O}_{6}{ }^{2-}$ will occur as well, but it is unimportant in this system. Table 1 shows the complete reaction mechanism that was used here to analyze the experimental data available in the literature. All the equilibria are established rapidly, and they are essentially maintained during the subsequent reaction. For the purpose of computer simulations the following forward or reverse rate coefficients were taken from the literature and combined with the established equilibrium constants $\left(\mu=1.0 \mathrm{~mol} \mathrm{dm}{ }^{-3}\right): k_{\mathrm{h} 1 \mathrm{f}}=2.0 \times 10^{7},{ }^{50} k_{\mathrm{d} 1 \mathrm{r}}=$ $2.0 \times 10^{8},{ }^{51} k_{\mathrm{d} 3 \mathrm{r}}=1.0 \times 10^{11},{ }^{51} k_{\mathrm{c} 4 \mathrm{f}}=6.3 \times 10^{3},{ }^{50} k_{\mathrm{c} 1 \mathrm{f}}=4.0 \times$ $10^{6} \cdot{ }^{18}$ Rate coefficients for some of the reactions following the formation of the complexes are known; appropriate references are indicated in Table 1 . The analysis will begin with the results of Carlyle and Zeck, ${ }^{12}$ as they have reported the most extensive data set. The conclusions reached will then provide a basis for discussing the results of the other authors.

\section{Analysis of the data of Carlyle and Zeck}

In their study the course of the overall reaction was followed by monitoring the optical absorption of the Fe(III) complex at wavelengths in the region $320-443 \mathrm{~nm}$ as a proxy for $\mathrm{Fe}(\mathrm{III})$. In all experiments the temperature was $25{ }^{\circ} \mathrm{C}$ and the ionic

Table 1 Reaction mechanism for the oxidation of S(IV) by Fe(III) in the absence of oxygen under conditions of low pH $(\mu=1.0)^{a}$

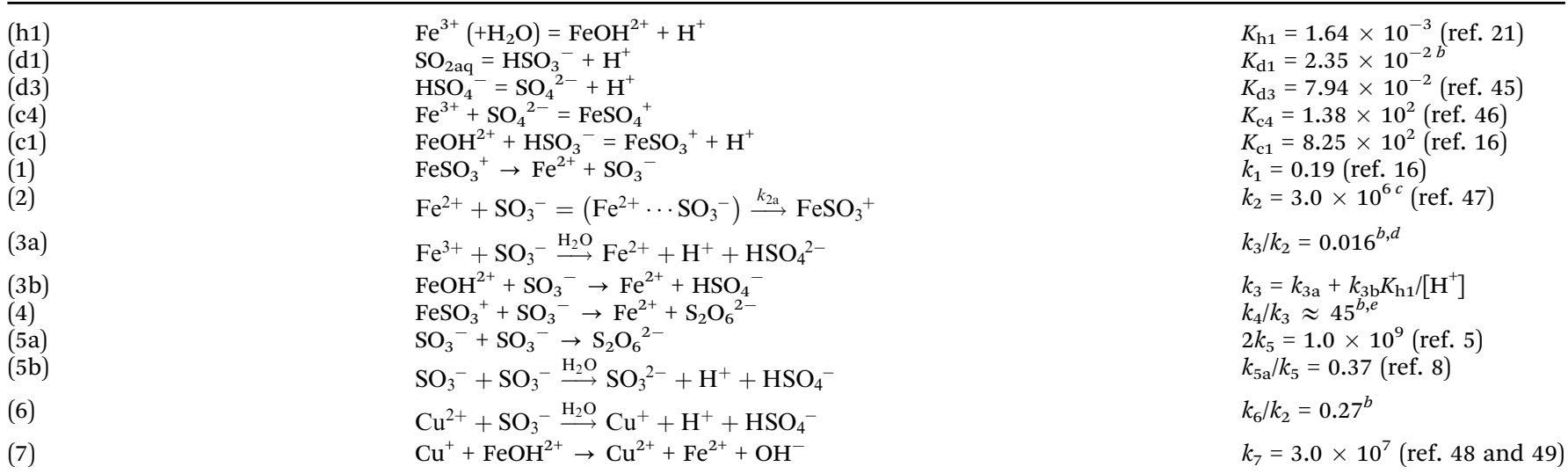

${ }^{a}$ Reference numbers are shown in parentheses. Units of equilibrium constants and rate coefficients are in mol, $\mathrm{dm}^{3}$, $\mathrm{s} .{ }^{b}$ Present data. ${ }^{c}$ Adjusted from $1.2 \times 10^{7}$ at $\mu=0.07 .{ }^{d}\left[\mathrm{H}^{+}\right]=0.255 \mathrm{~mol} \mathrm{dm}^{-3} .{ }^{e}\left[\mathrm{H}^{+}\right]=0.1 \mathrm{~mol} \mathrm{dm}^{-3}$. 
strength was $\mu=1.0 \mathrm{~mol} \mathrm{dm}{ }^{-3}$. Rate measurements were done mostly with $\mathrm{Fe}(\mathrm{II})$ in excess of $\mathrm{Fe}(\mathrm{III})$ while maintaining $\left[\mathrm{S}_{\mathrm{IV}}\right]>$ $\left[\mathrm{Fe}_{\mathrm{III}}\right]$. The main series of experiments were carried out by setting $\left[\mathrm{H}^{+}\right]=0.043$ or $\left[\mathrm{H}^{+}\right]=0.129\left(\mathrm{~mol} \mathrm{dm}{ }^{-3}\right)$.

With the notation $\left[\mathrm{Fe}_{\mathrm{III}}\right]=\left[\mathrm{Fe}^{3+}\right]+\left[\mathrm{FeOH}^{2+}\right]+\left[\mathrm{FeSO}_{3}^{+}\right]=$ $\left[\mathrm{Fe}^{3+}\right]\left\{\left(1+K_{\mathrm{h} 1} /\left[\mathrm{H}^{+}\right]\right)+A\left[\mathrm{~S}_{\mathrm{IV}}\right]\right\}$, and making use of the steady state assumption $\mathrm{d}\left[\mathrm{SO}_{3}{ }^{-}\right] / \mathrm{d} t \approx 0$, one obtains the following equation for the $\left[\mathrm{Fe}_{\mathrm{III}}\right]$ loss rate

$$
\frac{\mathrm{d}\left[\mathrm{Fe}_{\mathrm{II}}\right]}{\mathrm{d} t}=\frac{-\mathrm{d}\left[\mathrm{Fe}_{\mathrm{III}}\right]}{\mathrm{d} t}=\frac{2 k_{1}\left[\mathrm{Fe}_{\mathrm{III}}\right]^{2} A\left[\mathrm{~S}_{\mathrm{IV}}\right]}{\left[\mathrm{Fe}^{2+}\right] N\left(A_{0}+A\left[\mathrm{~S}_{\mathrm{IV}}\right]\right)^{2}} \frac{k_{3}}{k_{2}}\left(1+\frac{k_{4}}{k_{3}} A\left[\mathrm{~S}_{\mathrm{IV}}\right]\right)
$$

Here, $A_{0}=1+K_{\mathrm{h} 1} /\left[\mathrm{H}^{+}\right]$and $A=K_{\mathrm{c} 1 \mathrm{a}} /\left[\mathrm{H}^{+}\right]\left(1+\left[\mathrm{H}^{+}\right] / K_{\mathrm{d} 1}\right)$, with $K_{\mathrm{c} 1 \mathrm{a}}=K_{\mathrm{c} 1} K_{\mathrm{h} 1}$. The principal parameters determining the reaction rate are $k_{1} A$ and the ratios $k_{3} / k_{2}$ and $k_{4} / k_{3}$. The factor $N$ in the denominator of eqn (10) is

$$
N=1+\frac{k_{3}\left[\mathrm{Fe}^{3+}\right]}{k_{2}\left[\mathrm{Fe}^{2+}\right]}\left(1+\frac{k_{4}}{k_{3}} A\left[\mathrm{~S}_{\mathrm{IV}}\right]\right)
$$

It turns out that $N \approx 1$ so long as $\left[\mathrm{Fe}^{2+}\right]>\left[\mathrm{Fe}^{3+}\right]$. The rate coefficient $k_{3}$ replaces the individual rate coefficients of reactions (3a) and (3b) in Table 1 as it is not possible to separate the two processes here:

$$
k_{3}=k_{3 \mathrm{a}}+k_{3 \mathrm{~b}} K_{\mathrm{h} 1} /\left[\mathrm{H}^{+}\right]
$$

The above eqn (10) agrees well with the empirical rate law found by Carlyle and Zeck, ${ }^{12}$ in particular with the second order behavior of $\left[\mathrm{Fe}_{\mathrm{III}}\right]$, the increase of the rate with $a\left[\mathrm{~S}_{\mathrm{IV}}\right]+b\left[\mathrm{~S}_{\mathrm{IV}}\right]^{2}$, and the dependence on the reciprocal of $\left[\mathrm{Fe}^{2+}\right]$. The good agreement supports the applied reaction mechanism and suggests that the rate data reported can be used to estimate the ratio of the rate coefficients $k_{4} / k_{3}$. For this purpose eqn (10) is rearranged in the form

$$
R=k_{\mathrm{obs}}\left[\mathrm{Fe}^{2+}\right]_{\mathrm{o}}\left(A_{0}+A\left[\mathrm{~S}_{\mathrm{IV}}\right]\right)^{2} / A\left[\mathrm{~S}_{\mathrm{IV}}\right]=2\left(k_{1} k_{3} / k_{2}\right)\left(1+\left(k_{4} / k_{3}\right) A\left[\mathrm{~S}_{\mathrm{IV}}\right]\right)
$$

where $k_{\text {obs }}=\mathrm{d}\left[\mathrm{Fe}_{\mathrm{III}}\right] /\left[\mathrm{Fe}_{\mathrm{III}}\right]^{2} \mathrm{~d} t$ is the empirical rate coefficient. The quantities $k_{\mathrm{obs}},\left[\mathrm{Fe}^{2+}\right]_{0}$ and $\left[\mathrm{S}_{\mathrm{IV}}\right]_{0}$, given by Carlyle and Zeck ${ }^{12}$ for each experiment (their Table 2), were used to calculate $R$. If the assumptions made are applicable, a plot of $R$ versus $A\left[\mathrm{~S}_{\mathrm{IV}}\right]$ should yield a straight line with the slope being determined by $\left(k_{4} / k_{3}\right)$ and the intercept with the ordinate representing $2\left(k_{1} k_{3} / k_{2}\right)$. This relation is indeed observed as Fig. 6a illustrates.

Some of the experiments in this series were carried out with rather high concentrations of S(Iv) compared to those of $\mathrm{Fe}(\mathrm{III})$, causing the presence of higher $\mathrm{Fe}(\mathrm{III})-\mathrm{S}$ (IV) complexes in addition to the 1:1-complex. Computer calculations of the equilibria established between the three complexes indicated that the higher complexes begin to interfere when $\left[\mathrm{HSO}_{3}{ }^{-}\right] /\left[\mathrm{Fe}_{\mathrm{III}}\right]>$ $\sim 50$, that is $\left[\mathrm{S}_{\mathrm{IV}}\right] /\left[\mathrm{Fe}_{\mathrm{III}}\right] \approx 150$, when $\left[\mathrm{H}^{+}\right]=0.043 \mathrm{M}$, and $\left[\mathrm{S}_{\mathrm{IV}}\right] /$ $\left[\mathrm{Fe}_{\mathrm{III}}\right] \approx 300$ when $\left[\mathrm{H}^{+}\right]=0.129 \mathrm{M}$. Since the above eqn (10) is based on the assumption that only the 1 :1-complex is present the results of those experiments that did not satisfy this condition were not used. This removes 8 data points from a total set of 25 . The remaining data were subjected to a linear regression
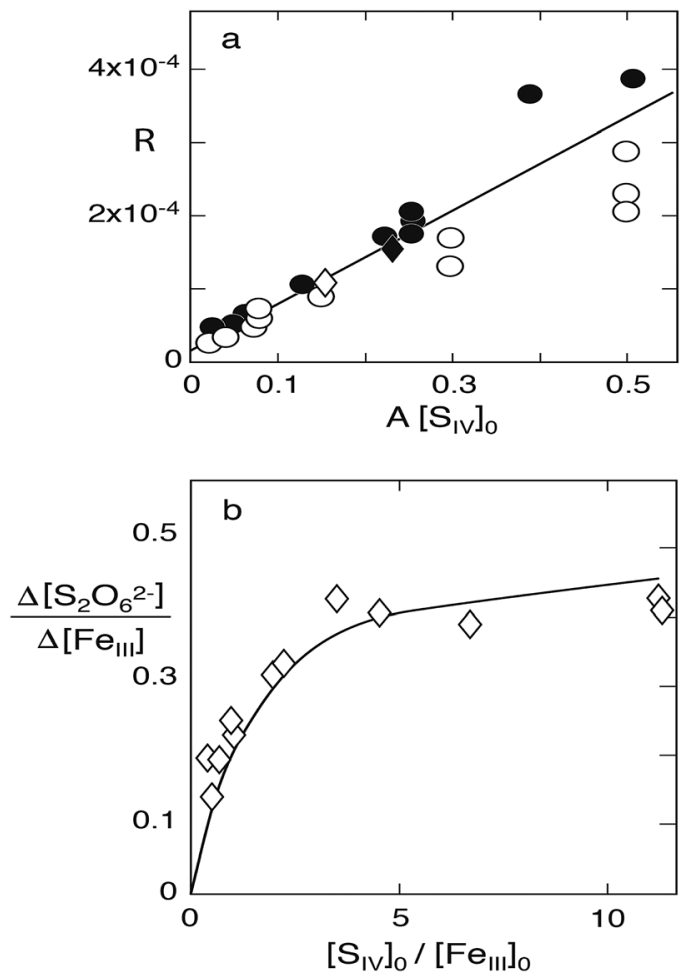

Fig. 6 Reaction of S(IV) with Fe(III) in the absence of oxygen. (a) Plot of $R$ versus $A\left[\mathrm{~S}_{\mathrm{IV}}\right]$ to test the validity of eqn (10), experimental data of Carlyle and Zeck: ${ }^{12}$ points $\left[\mathrm{H}^{+}\right]=0.043$, circles $\left[\mathrm{H}^{+}\right]=0.129$, open diamond $\left[\mathrm{H}^{+}\right]=0.086$, filled diamond, $\left[\mathrm{H}^{+}\right]=0.03\left(\mathrm{~mol} \mathrm{dm}{ }^{-3}\right)$; only data points below $A\left[\mathrm{~S}_{\mathrm{IV}}\right]=0.3$ were used in calculating the linear regression line shown. (b) Dithionate formation at $\left[\mathrm{H}^{+}\right]=0.1 \mathrm{~mol} \mathrm{dm}{ }^{-3}$ : points represent the measured ratio $\left[\mathrm{S}_{2} \mathrm{O}_{6}{ }^{2-}\right]_{\infty} /\left[\mathrm{Fe}_{\| I}\right]_{0}$; the solid line was calculated with $k_{4} / k_{3}=45$.

treatment that resulted in a slope of $(6.7 \pm 0.4) \times 10^{-4} \mathrm{~s}^{-1}$ and an intercept with the ordinate of $(1.6 \pm 1.2) \times 10^{-5} \mathrm{~s}^{-1}$. According to eqn (10a) the slope and the intercept are equivalent to $2\left(k_{1} k_{3} / k_{2}\right)\left(k_{4} / k_{3}\right)$ and $2\left(k_{1} k_{3} / k_{2}\right)$, respectively. Their ratio is $k_{4} / k_{3}=42$ with a large margin of error due to the uncertainty associated with the value of the intercept.

These data do not allow a determination of the value of $k_{3} / k_{2}$, because the second order rate coefficients $k_{\mathrm{obs}}$ reported are not calibrated. The data can only describe the influence of important parameters on the reaction rate. In contrast to the exponential behavior of first order reactions, the decay of a reactant undergoing a second order reaction follows the rate law $1 / x=1 / x_{0}+k_{\text {obs }} t$. Due to experimental difficulties Carlyle and $\mathrm{Zeck}^{12}$ could not determine $x_{0}$, and for $k_{\mathrm{obs}} t$ much larger than $1 / x_{0}$ the initial signature of $x_{0}$ is lost. However, the value of $k_{3} / k_{2}$ can be estimated from other data discussed further below, in which the rise of $\mathrm{Fe}$ (II) was observed as a function of time.

Carlyle and Zeck ${ }^{12}$ have also measured, in separate experiments, the yield of dithionate under various conditions (their Table 1). In this study the concentration of $\mathrm{Fe}(\mathrm{III})$ was raised to $\left[\mathrm{Fe}_{\mathrm{III}}\right]_{0} \approx$ $0.01 \mathrm{~mol} \mathrm{dm}^{-3}$ compared to $\left[\mathrm{Fe}_{\mathrm{III}}\right]_{0} \approx(3-5) \times 10^{-4} \mathrm{~mol} \mathrm{dm}^{-3}$ in the reaction rate measurements; $\left[\mathrm{S}_{\mathrm{IV}}\right]_{0} /\left[\mathrm{Fe}_{\mathrm{III}}\right]_{0}$ ranged from 0.4 to 11 , approximately, and the hydrogen ion concentration was $\left[\mathrm{H}^{+}\right]=0.1$ in most cases. Only these data are considered here. The extent of dithionate production predicted by the reaction system shown in 
Table 1 was explored by computer simulations and the yields obtained were compared with those determined experimentally. The experimental data are for $\left[\mathrm{S}_{\mathrm{V}}\right]_{\infty}=2\left[\mathrm{~S}_{2} \mathrm{O}_{6}{ }^{2-}\right]_{\infty}$, that is, the reaction was assumed to have gone to completion, but the time periods between starting the reaction and the final product analysis were not given. The computer calculations showed that for reasonable values of $k_{3} / k_{2}$ (vide infra) the reaction is essentially complete after $24 \mathrm{~h}$, but even after $12 \mathrm{~h}$ the amount of dithionate formed is already close to the final value. The calculations confirmed the prediction that the rate of dithionate formation slows down as the reaction proceeds, because the consumption of $\mathrm{S}$ (Iv) lowers the concentration of the $\mathrm{FeSO}_{3}{ }^{+}$complex as well. This effect diminishes with increasing excess of $\mathrm{S}$ (Iv) over Fe(III).

According to the stoichiometric equations associated with the reaction mechanism in Table 1

$$
\begin{gathered}
-\Delta\left[\mathrm{Fe}_{\mathrm{III}}\right]=\Delta\left[\mathrm{Fe}_{\mathrm{II}}\right]=2 \Delta\left[\mathrm{SO}_{4}{ }^{2-}\right]+2 \Delta\left[\mathrm{S}_{2} \mathrm{O}_{6}{ }^{2-}\right] \\
-\Delta\left[\mathrm{S}_{\mathrm{IV}}\right]=\Delta\left[\mathrm{SO}_{4}{ }^{2-}\right]+2 \Delta\left[\mathrm{S}_{2} \mathrm{O}_{6}{ }^{2-}\right]
\end{gathered}
$$

the rate of $\mathrm{Fe}(\mathrm{III})$ consumption is twice that of the production of sulfate plus dithionate so that the ratio $\left[\mathrm{S}_{2} \mathrm{O}_{6}{ }^{2-}\right]_{\infty} /\left[\mathrm{Fe}_{\mathrm{II}}\right]_{\infty}<$ 0.5. With $\left[\mathrm{S}_{\mathrm{IV}}\right]$ in excess, $\left[\mathrm{Fe}_{\mathrm{II}}\right]_{\infty} \approx\left[\mathrm{Fe}_{\mathrm{III}}\right]_{0}$. Thus, one may compare, as Carlyle and Zeck have done, $\left[\mathrm{S}_{2} \mathrm{O}_{6}{ }^{2-}\right]_{\infty} /\left[\mathrm{Fe}_{\mathrm{III}}\right]_{0}$ with the initial $\left[\mathrm{S}_{\mathrm{IV}}\right]_{0} /\left[\mathrm{Fe}_{\mathrm{III}}\right]_{0}$ concentration ratio. In those cases where $\left[\mathrm{Fe}_{\mathrm{III}}\right]_{0}>\left[\mathrm{S}_{\mathrm{IV}}\right]_{0}$ the consumption of $\left[\mathrm{S}_{\mathrm{IV}}\right]$ at the end of the reaction will be complete, hence one can calculate the corresponding $\Delta\left[\mathrm{Fe}_{\mathrm{III}}\right]$ from the above equations. Fig. $6 \mathrm{~b}$ shows that $\left[\mathrm{S}_{2} \mathrm{O}_{6}{ }^{2-}\right]_{\infty} / \Delta\left[\mathrm{Fe}_{\mathrm{III}}\right]_{\infty}$ rises with increasing $\left[\mathrm{S}_{\mathrm{IV}}\right]_{0} /\left[\mathrm{Fe}_{\mathrm{III}}\right]_{0}$ ratio as expected. The results of computer calculations were largely found to agree with the measurements. The best fit to the measurements, resulting in an average deviation of $5 \%$, was obtained with $k_{4} / k_{3}=45$. The solid line in Fig. 6b, which represents the calculated values, indicates the extent of agreement reached. Thereby it is demonstrated that the data reported by Carlyle and Zeck for the $\mathrm{Fe}(\mathrm{III})-\mathrm{S}(\mathrm{Iv})$ reaction system are selfconsistent and agree with the adopted reaction mechanism in essentially all respects.

\section{Comparison with other studies}

A direct comparison of the results of Carlyle and $\mathrm{Zeck}^{12}$ with those of other studies is not possible, not only because of the widely varying experimental conditions employed, but also because the data are not presented in a uniform manner. However, initial reaction rates and the production of dithionate were measured in most studies. Therefore, computer simulations were mostly used to determine how far the results are consistent with each other.

Karraker $^{11}$ sought to suppress the formation of dithionate by working with iron in large excess over S(Iv). In some experiments $\mathrm{Fe}(\mathrm{II})$ was added. The ionic strength was adjusted to $\mu \approx$ $1.0 \mathrm{~mol} \mathrm{dm}^{-3}$, and the hydrogen ion concentration was set to $\left[\mathrm{H}^{+}\right]=0.255$ except in three cases $(0.51,0.63,1.0)$. The rise of $\left[\mathrm{Fe}^{2+}\right]$ with time was measured and the half-rise time was determined. Assuming dithionate formation to be negligible, the stoichiometry is simplified to $\Delta\left[\mathrm{Fe}^{2+}\right]=-\Delta\left[\mathrm{Fe}_{\mathrm{III}}\right]=-2 \Delta\left[\mathrm{S}_{\mathrm{IV}}\right]$.
This allows one to replace in equation eqn (10): $-\mathrm{d}\left[\mathrm{Fe}_{\mathrm{III}}\right] / \mathrm{d} t$ by $-2 \mathrm{~d}\left[\mathrm{~S}_{\mathrm{IV}}\right] / \mathrm{d} t$, and $\left[\mathrm{Fe}^{2+}\right]$ by $\left[\mathrm{Fe}^{2+}\right]_{0}+2\left(\left[\mathrm{~S}_{\mathrm{IV}}\right]_{0}-\left[\mathrm{S}_{\mathrm{IV}}\right]\right)$, respectively. As $\left[\mathrm{Fe}_{\mathrm{III}}\right]$ stays nearly constant, the resulting expression can be integrated to yield

$$
\begin{aligned}
\left(\left[\mathrm{Fe}^{2+}\right]_{0}+2\left(\left[\mathrm{~S}_{\mathrm{IV}}\right]_{0}+\right.\right. & \left.\left.\left(k_{3} / k_{2}\right)\left[\mathrm{Fe}_{\mathrm{III}}\right]_{0}\right)\right) \ln \left(\left[\mathrm{S}_{\mathrm{IV}}\right] /\left[\mathrm{S}_{\mathrm{IV}}\right]_{0}+2\left(\left[\mathrm{~S}_{\mathrm{IV}}\right]_{0}-\left[\mathrm{S}_{\mathrm{IV}}\right]\right)\right) \\
& =-k_{1}\left(k_{3} / k_{2}\right) A\left[\mathrm{Fe}_{\mathrm{III}}\right]_{0}^{2} \Delta t
\end{aligned}
$$

where $A=K_{\mathrm{c} 1 \mathrm{a}} /\left[\mathrm{H}^{+}\right]\left(1+\left[\mathrm{H}^{+}\right] / K_{\mathrm{d} 1}\right)$ as before. Karraker considered the last term on the left to be negligible. By setting $\ln \left(\left[\mathrm{S}_{\mathrm{IV}}\right] /\right.$ $\left.\left[\mathrm{S}_{\mathrm{IV}}\right]_{0}\right)=-0.693$ for $\Delta t=\Delta t_{\frac{1}{2}}$ and rearranging eqn (13a), he derived an equation of the form

$$
\left[\mathrm{Fe}_{\mathrm{III}}\right]_{0} \Delta t_{\frac{1}{2}}=0.693\left\{\left(1 / k_{1} A\right)+\left(k_{2} / k_{3} k_{1} A\right)\left(\left[\mathrm{Fe}^{2+}\right]_{0}+2\left[\mathrm{~S}_{\mathrm{IV}}\right]_{0}\right) /\left[\mathrm{Fe}_{\mathrm{III}}\right]_{0}\right\}
$$

which is predicted to yield a straight line when the measured half-life times are plotted versus $\left(\left[\mathrm{Fe}^{2+}\right]_{0}+2\left[\mathrm{~S}_{\mathrm{IV}}\right]_{0}\right)$. Karraker ${ }^{11}$ used data from 10 runs with $\left[\mathrm{Fe}_{\mathrm{III}}\right]_{0}=0.0653$ and $\left[\mathrm{H}^{+}\right]=$ $0.255 \mathrm{~mol} \mathrm{dm}^{-3}$ and reported the prediction to be verified, but he did not show the associated plot. A plot of the quantity $\left[\mathrm{Fe}_{\mathrm{III}}\right]_{0} \Delta t_{\frac{1}{2}} / 0.693$ versus $\left(\left[\mathrm{Fe}^{2+}\right]_{0}+2\left[\mathrm{~S}_{\mathrm{IV}}\right]_{0}\right) /\left[\mathrm{Fe}_{\mathrm{III}}\right]_{0}$ is shown in Fig. 7a. Here, all the data for $\left[\mathrm{H}^{+}\right]=0.255 \mathrm{~mol} \mathrm{dm}^{-3}$ are used, including 3 data points where $\left[\mathrm{Fe}_{\mathrm{III}}\right]_{0}$ differs from 0.0653 . Most of the data are seen to fall on a straight line, confirming Karraker's claim. The linear regression line shown leads to an intercept with the ordinate of $0.191 \mathrm{~min}$, that is $k_{1} K_{\mathrm{c} 1 \mathrm{a}}=$ $0.26 \pm 0.07 \mathrm{~s}^{-1}$, while the slope of the straight line gives $k_{2} / k_{3}=$ $21.8 \pm 1.3$. These values agree with those reported by Karraker: $k_{1} A /\left[\mathrm{H}^{+}\right]=1.35 \mathrm{~min}^{-1}$, i.e. $k_{1} K_{\mathrm{c} 1 \mathrm{a}}=0.26 \mathrm{~s}^{-1}$, and $k_{2} / k_{3}=22$. Note that $k_{1} K_{\mathrm{c} 1 \mathrm{a}}=0.26$ is in close agreement with the value $0.256 \pm$ $0.03 \mathrm{~s}^{-1}$ found by Lente and Fabian ${ }^{16}$ from direct measurements. This agreement lends credence to Karraker's data and his method of analysis.

The ratio $k_{2} / k_{3} \approx 22$ can only be a coarse estimate, however, because dropping the term $2\left(\left[\mathrm{~S}_{\mathrm{IV}}\right]_{0}-\left[\mathrm{S}_{\mathrm{IV}}\right]\right)$ in eqn $(13 \mathrm{a})$ is not really justified. Although this term may be taken into account when evaluating the equation, it was considered more appropriate to determine $k_{2} / k_{3}$ by means of computer simulations. The procedure was to find the best fit between calculated and measured half-life times by varying $k_{2} / k_{3}$ in a narrow range. The calculations made use of $k_{4} / k_{3}=42$ determined from the data of Carlyle and Zeck. ${ }^{12}$ This gave $\left[\mathrm{S}_{2} \mathrm{O}_{6}{ }^{2-}\right] /\left[\mathrm{S}_{\mathrm{VI}}\right]$ ratios rising with the $\left[\mathrm{S}_{\mathrm{IV}}\right]_{0}$ concentration as expected but still staying in the low percentage range. The best fit between calculated and measured half-life times for $k_{1} K_{\mathrm{c} 1 \mathrm{a}}=0.256 \mathrm{~s}^{-1}$ was obtained with $k_{2} / k_{3}=61.4 \pm 3.0$. Fig. $7 \mathrm{~b}$ shows the agreement that is reached. The average deviation of the points from the $1: 1$ line is about $3 \%$. Fig. $7 \mathrm{~b}$ includes all the data with $\left[\mathrm{H}^{+}\right]=0.255$, except the two points obtained when $\left[\mathrm{Fe}^{2+}\right]_{0}>\left[\mathrm{S}_{\mathrm{IV}}\right]_{0}$ as they are off-scale. In this case the calculated half-life times are 17 and $31.7 \mathrm{~min}$, whereas the measured values were 10.2 and $13.7 \mathrm{~min}$, respectively. It appears that when larger amounts of $\mathrm{Fe}(\mathrm{II})$ are added the measurement of half-life times become less precise. The three data points at different hydrogen ion concentrations were already discarded by Karraker; they do not fit into any scheme. 

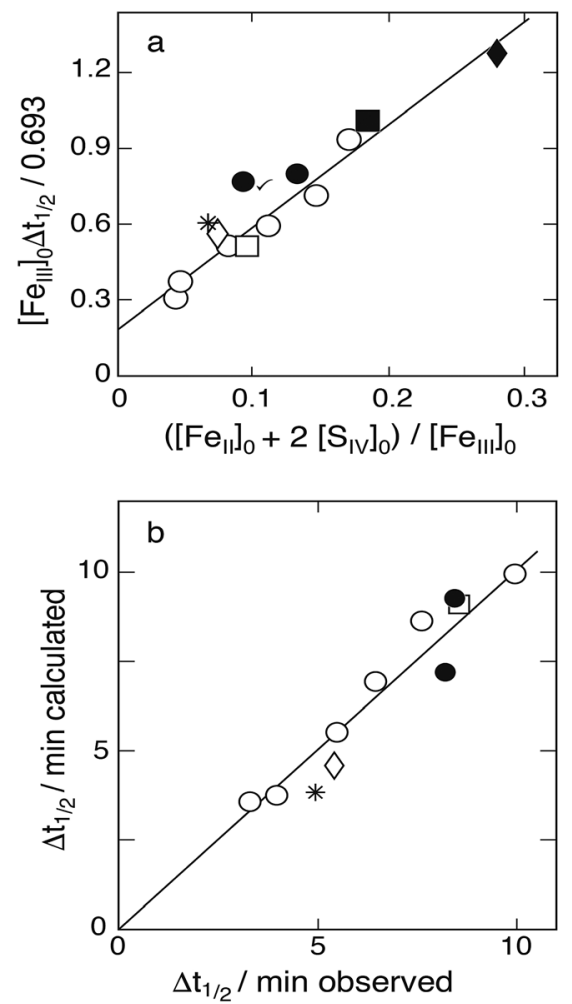

Fig. 7 (a) Plot of $\left[\mathrm{Fe}_{I I I}\right]_{0} \Delta t \frac{1}{2}$ versus $\left(\left[\mathrm{Fe}^{2+}\right]_{0}+2\left[\mathrm{~S}_{\mathrm{IV}}\right]_{0}\right) /\left[\mathrm{Fe}_{I I I}\right]_{0}$ to test the applicability of eqn (13b) in evaluating the data of Karraker; ${ }^{11}$ initial concentrations $\left(\mathrm{mmol} \mathrm{dm}^{-3}\right)$ : [ $\left.\mathrm{S}_{\mathrm{IV}}\right]_{0}$ : 1.35-5.53, [Fe $\mathrm{FII}_{0}$ : circles 65.3, asterisk 89.0, open diamond 75.0, open square 13.1; $\left[\mathrm{Fe}^{2+}\right]$ added: points 0.9 , solid square 4.93 , solid diamond 11.4 . The linear regression line excludes the marked point. (b) Comparison of calculated and measured reaction halflife times. The straight line is the $1: 1$ relation obtained with $k_{1} / k_{2}=61.4$

Higginson and Marshall ${ }^{9}$ and Pollard et al., ${ }^{10}$ in contrast to other investigators, have used in their experiments hydrogen sulfate and sulfuric acid, respectively, to adjust the hydrogen ion concentration. The consequence is that most of the $\mathrm{Fe}(\mathrm{III})$ is bound to $\mathrm{SO}_{4}{ }^{2-}$ in the strong $\mathrm{FeSO}_{4}{ }^{+}$complex, leaving only a few percent of $\mathrm{Fe}(\mathrm{III})$ available as free $\mathrm{Fe}^{3+}$ and $\mathrm{FeOH}^{2+}$. If the $\mathrm{FeSO}_{4}{ }^{+}$complex is chemically inactive, it will merely provide a reservoir of free $\left[\mathrm{Fe}_{\mathrm{III}}\right]$, but the reaction rate will be strongly reduced in comparison to the situation when sulfate is not initially present. Taking the $\mathrm{FeSO}_{4}{ }^{+}$complex to be chemically inert, computer simulations reproduced the results of Higginson and Marshall ${ }^{9}$ only approximately, when the ratio $k_{2} / k_{3}=61.4$ was used in the calculations. In these experiments the hydrogen ion

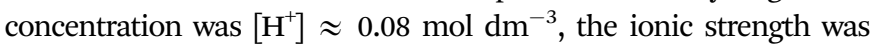
$\mu=2.0 \mathrm{~mol} \mathrm{dm}^{-3}$, and $\mathrm{Fe}(\mathrm{II})$ was added. Pollard et al. ${ }^{10}$ did not control the ionic strength, but at the high concentrations used in the experiments it was found to stay approximately constant at $\mu \approx 0.9 \mathrm{~mol} \mathrm{dm}^{-3}$. When $\mathrm{Fe}(\mathrm{II})$ was added, the ionic strength rose to $\mu \approx 1.7 \mathrm{~mol} \mathrm{dm}^{-3}$. The hydrogen ion concentration was $\left[\mathrm{H}^{+}\right] \approx$ $0.5 \mathrm{~mol} \mathrm{dm}^{-3}$. Both groups of investigators presented their results as rates $\left(\Delta\left[\mathrm{Fe}_{\mathrm{II}}\right] / \Delta t\right.$ and $\left.\Delta\left[\mathrm{S}_{2} \mathrm{O}_{6}{ }^{2-}\right] / \Delta t\right)$ during the initial stage of the reaction, but Pollard et al. ${ }^{10}$ have in one case explored the course of the reaction over a period of $24 \mathrm{~h}$. They treated the reaction as bimolecular and plotted the logarithm of the ratio

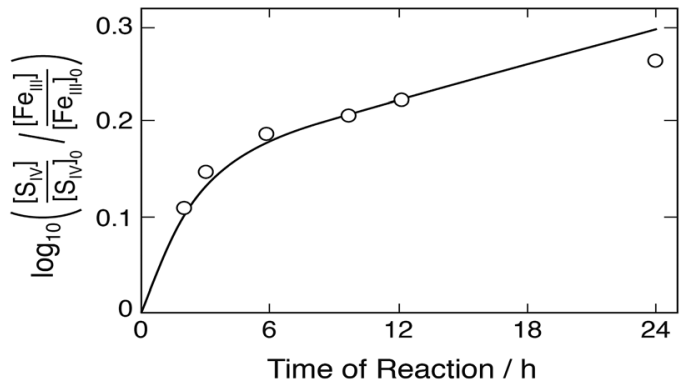

Fig. 8 Rate of the Fe(III)-S(IV) reaction (assumed to be bimolecular) as a function of time according to Pollard et al. ${ }^{10}$ Points represent measurements, the solid line was calculated. Initial concentrations $\left(\mathrm{mol} \mathrm{dm}{ }^{-3}\right)$ : $\left[\mathrm{Fe}_{I I I}\right]_{0}=0.2$, $\left[\mathrm{S}_{\mathrm{IV}}\right]_{0}=0.0468,\left[\mathrm{H}^{+}\right]=0.5$; derived initial concentrations due to the presence of sulfates $\left[\mathrm{FeSO}_{4}{ }^{+}\right]=0.186,\left[\mathrm{Fe}^{3+}\right]=0.0136,\left[\mathrm{HSO}_{4}{ }^{-}\right]=0.809$, $\left[\mathrm{SO}_{4}{ }^{2-}\right]=0.09$

of the reactant loss rates versus time. Fig. 8 compares their measurements with computer simulations. The solid line was obtained with $k_{2} / k_{3}=61.4$ and this value could also reproduce their other rate data, thus providing some support for the value of $k_{2} / k_{3}$ derived above.

With regard to dithionate one should note that the mechanism in Table 1 predicts the relative production rate $\Delta\left[\mathrm{S}_{2} \mathrm{O}_{6}{ }^{2-}\right] / \Delta\left[\mathrm{Fe}^{2+}\right]$ to depend primarily on $A\left[\mathrm{~S}_{\mathrm{IV}}\right]$, because this factor determines the concentration of the $\mathrm{FeSO}_{3}{ }^{+}$complex. As $A$ involves the equilibrium constants $K_{\mathrm{c} 1}, K_{\mathrm{h} 1}$ and $K_{\mathrm{d} 1}$ in addition to the hydrogen ion concentration, the ionic strength dependence of the equilibrium constants as well as differences in $\left[\mathrm{H}^{+}\right]$must be taken into account when comparing the ratio $\Delta\left[\mathrm{S}_{2} \mathrm{O}_{6}{ }^{2-}\right] / \Delta[\mathrm{Fe}]$ observed in the different studies. Fig. 9 compares this ratio as a function of $A\left[\mathrm{~S}_{\mathrm{IV}}\right]$. While the data of Higginson and Marshall ${ }^{9}$ and of Carlyle and Zeck ${ }^{12}$ are approximately in agreement, much higher relative dithionate production rates were obtained by Pollard et al. ${ }^{10}$ and by Dasgupta $e t$ al. ${ }^{13}$ The latter authors, in fact, found dithionate to be the exclusive $\mathrm{S}$ (Iv) oxidation product. The incongruity of the data is perturbing, but may have its origin in analytical difficulties. The classical analytical procedure that most authors have used, involves the oxidation of dithionate to sulfate by dichromate. The oxidant is added in excess, and the surplus is then determined by back-titration. This procedure requires the prior removal of all

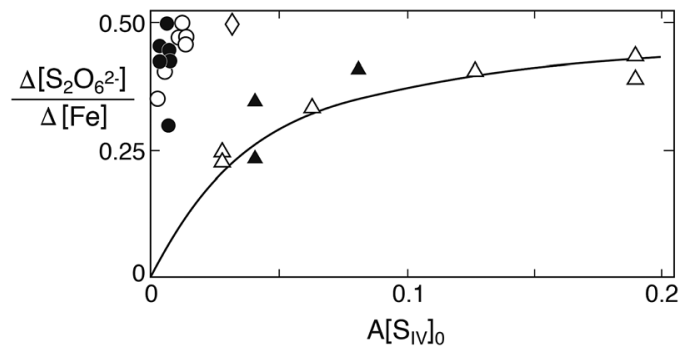

Fig. 9 Relative rate of dithionate production as a function of $A\left[\mathrm{~S}_{\mathrm{IV}}\right]_{0}$. Comparison of results obtained in different studies: circles $A=0.136$, points (Fe(॥) added) $A=0.078$ (Pollard et al. ${ }^{10}$ ); diamond, $A=6.22$ (Dasgupta et al. ${ }^{13}$ ); filled triangles, $A=2.04$ (Higginson and Marshall ${ }^{9}$ ); open triangles, $A=2.57$ (Carlyle and $Z Z \mathrm{Ck}^{12}$ ). The solid line was calculated with $k_{4} / k_{3}=45$. 
interfering substances (metal ions, sulfite, etc.). Carlyle and Zeck ${ }^{12}$ have measured dichromate by spectrophotometry, which is more accurate than titration, whereas Dasgupta et al. ${ }^{13}$ have used $\mathrm{HNO}_{3}$ as oxidant and determined the amount of sulfate produced. This method is the least reliable, because it rests on the prior removal of sulfate produced during the reaction. In view of the good agreement of the results obtained by Carlyle and Zeck ${ }^{12}$ with the proposed reaction mechanism, and the agreement of their rate data with dithionate production rates, their results are presently the most convincing. But the comparison shows that the extent of dithionate production in this reaction is not settled and should be reexamined with modern analytical techniques such as ion chromatography.

\section{The role of copper as a catalyst}

The addition of copper to the solution reduces the rate of dithionate formation. This effect is only weakly apparent in the results of Higginson and Marshall ${ }^{9}$ due to the scatter of the data, but the results of Carlyle and $\mathrm{Zeck}^{12}$ show it quite clearly. A concentration of $\mathrm{Cu}$ (II) similar to that of $\mathrm{Fe}(\mathrm{III})$ reduces the rate of dithionate production to about one third of that in the absence of copper. In the mechanism proposed by Higginson and Marshall ${ }^{9}$ the effect arises from the role of copper as an efficient $\mathrm{SO}_{3}{ }^{-}$radical scavenger. Dithionate production rates measured by Carlyle and Zeck ${ }^{12}$ included two experiments, in which copper was added. The measured decrease of dithionate production could be adequately reproduced by computer simulations when the rate coefficient for the reaction of $\mathrm{SO}_{3}{ }^{-}$with $\mathrm{Cu}$ (II) was assumed to be about ten times greater than that with $\mathrm{Fe}(\mathrm{III})$, that is $k_{6} / k_{3} \approx 10$. Carlyle and Zeck have conducted an extensive series of experiments to explore the influence of copper on the rate of the Fe(III)-S(IV) reaction. The majority of the experiments were carried out with $\mathrm{S}$ (Iv) in excess over $\mathrm{Fe}(\mathrm{III})$, with $\left[\mathrm{Fe}^{2+}\right]>10\left[\mathrm{Fe}^{3+}\right]$, and with $\left[\mathrm{H}^{+}\right]$set to $0.03,0.043$, or $0.086 \mathrm{~mol} \mathrm{dm}^{-3}$. The results of these runs were subjected to a detailed analysis.

As Table 1 indicates, the reaction with $\mathrm{SO}_{3}{ }^{-}$converts $\mathrm{Cu}$ (II) to $\mathrm{Cu}(\mathrm{I})$, which then reacts (more rapidly) with $\mathrm{Fe}(\mathrm{III})$ to restore $\mathrm{Cu}(\mathrm{II})$. The second reaction has been studied by means of pulse radiolysis ${ }^{48,49}$ and was found to proceed primarily via the $\mathrm{FeOH}^{2+}$ complex. If these two reactions are the only ones involving copper, the concentration of $\mathrm{Cu}(\mathrm{I})$ will be kept in a steady state with $\mathrm{Cu}(\mathrm{II})$, that is $\left[\mathrm{Cu}^{+}\right] /\left[\mathrm{Cu}^{2+}\right]=k_{6}\left[\mathrm{SO}_{3}{ }^{-}\right] / k_{7}\left[\mathrm{FeOH}^{2+}\right]$. This relation can be used together with the steady state assumption $\mathrm{d}\left[\mathrm{SO}_{3}{ }^{-}\right] / \mathrm{d} t \approx 0$ to modify eqn (10) so as to include the additional reactions of copper. The kinetic equation thus obtained is

$\frac{-\mathrm{d}\left[\mathrm{Fe}_{\mathrm{III}}\right]}{\mathrm{d} t}=\frac{2 k_{1} A\left[\mathrm{Fe}_{\mathrm{III}}\right]\left[\mathrm{S}_{\mathrm{IV}}\right]}{\left(A_{0}+A\left[\mathrm{~S}_{\mathrm{IV}}\right]\right)} \frac{\left(k_{3}\left[\mathrm{Fe}^{3+}\right]\left(1+\frac{k_{4}}{k_{3}} A[\mathrm{~S} \mathrm{IV}]\right)+k_{6}\left[\mathrm{Cu}^{2+}\right]\right)}{k_{2}\left[\mathrm{Fe}^{2+}\right] N_{1}}$

Here the factor $N$ in the denominator of eqn (10) is replaced by

$$
N_{1}=1+\frac{k_{3}\left[\mathrm{Fe}^{3+}\right]}{k_{2}\left[\mathrm{Fe}^{2+}\right]}\left(1+\frac{k_{4}}{k_{3}} A[\mathrm{~S} \mathrm{IV}]\right)+\frac{k_{6}\left[\mathrm{Cu}^{2+}\right]}{k_{2}\left[\mathrm{Fe}^{2+}\right]}
$$

As before, under conditions when $\left[\mathrm{F}^{2+}\right]>\left[\mathrm{Fe}^{3+}\right]$, the second term in $N_{1}$ becomes much smaller than unity. The further analysis showed that except for very low concentrations of copper, the third term is also smaller than the fourth, $k_{6}\left[\mathrm{Cu}^{2+}\right] / k_{2}\left[\mathrm{Fe}^{2+}\right]$, so that eqn $(10 \mathrm{~b})$ reduces to

$$
\frac{-\mathrm{d}\left[\mathrm{Fe}_{\mathrm{III}}\right]}{\left[\mathrm{Fe}_{\mathrm{III}}\right] \mathrm{d} t}=k_{\mathrm{obs}}{ }^{\prime}=\frac{2 k_{1} A\left[\mathrm{~S}_{\mathrm{IV}}\right]}{\left(A_{0}+A[\mathrm{~S} \mathrm{IV}]\right)}\left(\frac{k_{6}\left[\mathrm{Cu}^{2+}\right]}{k_{2}\left[\mathrm{Fe}^{2+}\right]+k_{6}\left[\mathrm{Cu}^{2+}\right]}\right)
$$

This equation agrees with the empirical rate law reported by Carlyle and Zeck ${ }^{12}$ except for a term quadratic in $\left[\mathrm{Cu}^{2+}\right]$ in the denominator of their expression. It is interesting to note that in contrast to the second order rate behavior observed when copper is absent (eqn (10)), the rate law changes to one of first order in the presence of copper. The change is evident from the data of Carlyle and Zeck as well as from a comparison of eqn (10) and (10c). It may be taken to provide a further confirmation of the adopted mechanism. For the purpose of analysis it is convenient to rearrange the equation as follows

$$
Z=\frac{2 k_{1} A[\mathrm{~S} \mathrm{IV}]}{k_{\mathrm{obs}}{ }^{\prime}\left(A_{0}+A\left[\mathrm{~S}_{\mathrm{IV}}\right]\right)}=\left(1+\frac{k_{2}\left[\mathrm{Fe}^{2+}\right]}{k_{6}\left[\mathrm{Cu}^{2+}\right]}\right)
$$

In this form the equation predicts that a plot of $Z$ versus the ratio $\left[\mathrm{Fe}^{2+}\right] /\left[\mathrm{Cu}^{2+}\right]$ should yield a straight line with the slope being determined by $\left(k_{2} / k_{6}\right)$. Fig. 10 shows the corresponding plot. Here, the results of 22 experiments were used for which the above-mentioned conditions apply. While a linear relationship is clearly observed, it is also evident that a crowding of data points occurs in the region near the origin. This effect arises from the high concentration of copper used in 13 of the experiments. Despite the uneven distribution, a linear regression analysis shows the data to fall on a straight line with remarkably little variance. The line intersects the ordinate at $1.04 \pm 0.17$, and the slope is $k_{2} / k_{6}=3.7 \pm 0.3$.

\section{Rate coefficients}

The foregoing results suggest that apart from the chosen initial conditions, the rate of the reaction is defined by the rate coefficient $k_{1}$ for the decomposition of the $\mathrm{FeSO}_{3}{ }^{+}$complex, and by the ratios of rate coefficients $k_{2} / k_{3}, k_{4} / k_{3}$, and $k_{2} / k_{6}$. To determine the individual rate coefficients requires separate measurements. Only one such study appears to exist. Buxton et $a l .{ }^{47}$ have studied reaction (2) by means of the pulse radiolysis technique and found the reaction to proceed via an intermediate complex, which is in fast equilibrium with the reactants $\mathrm{SO}_{3}{ }^{-}$and $\mathrm{Fe}^{2+}$. The pre-equilibrium constant was determined to be $K_{2}=278$, and the rate coefficient for the forward reaction $k_{2 \mathrm{a}}=3.05 \times 10^{4} \mathrm{~s}^{-1}$ at $20{ }^{\circ} \mathrm{C}$. The overall rate coefficient then is $k_{2}=8.5 \times 10^{6} \mathrm{dm}^{3} \mathrm{~mol}^{-1} \mathrm{~s}^{-1}$. The value at $25{ }^{\circ} \mathrm{C}$ can be estimated by means of the activation energy, $46.6 \mathrm{~kJ} \mathrm{~mol}^{-1}$, measured over the temperature range $20-30{ }^{\circ} \mathrm{C}$ : $k_{2}=1.2 \times 10^{7} \mathrm{dm}^{3} \mathrm{~mol}^{-1} \mathrm{~s}^{-1}$. Unfortunately, the value refers to an ionic strength of $\mu=0.07$ rather than $\mu=1.0 \mathrm{~mol} \mathrm{dm}^{-3}$ as required here. All reactions between ions in aqueous solution 


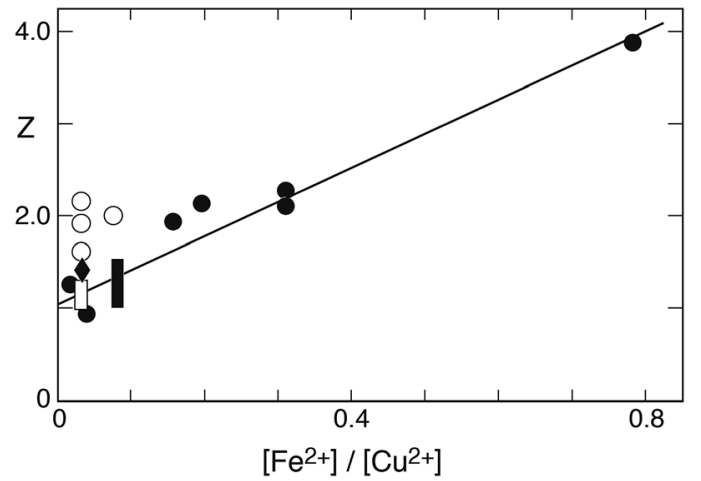

Fig. 10 Plot of $Z=2 k_{0} A\left[S_{\mathrm{VV}}\right] / k_{\mathrm{obs}}{ }^{\prime}\left(A_{0}+A\left[\mathrm{~S}_{\mathrm{VV}}\right]\right)$ versus the concentration ratio $\left[\mathrm{Fe}^{2+}\right] /\left[\mathrm{Cu}^{2+}\right]$ to test the applicability of eqn $(10 \mathrm{c})$ in evaluating the data of Carlyle and Zeck; ${ }^{12}$ initial concentrations $\left(\mathrm{mmol} \mathrm{dm}^{-3}\right)$ : $\left[\mathrm{Fe}^{3+}\right]_{0} 0.3$ or 0.5, $\left[\mathrm{S}_{\mathrm{IV}}\right]_{0} 0.844-51.6,\left[\mathrm{Fe}^{2+}\right]_{0} 3.37$, predominantly, $\mu=1.0$; points $\left[\mathrm{H}^{+}\right]=$ 0.043 , diamond $\left[\mathrm{H}^{+}\right]=0.03$, open box (5 values) $\left[\mathrm{H}^{+}\right]=0.086\left(\mathrm{~mol} \mathrm{dm}^{-3}\right)$. The open points were deleted in deriving the linear regression line.

are known to depend on the ionic strength. ${ }^{52}$ It is customary to express this dependence by the modified Brønsted-Bjerrum relation $\log k=\log ^{0} k+1.02 z_{\mathrm{A}} z_{\mathrm{B}} \mu^{\frac{1}{2}} /\left(1+\mu^{\frac{1}{2}}\right)$, where $z_{\mathrm{A}}$ and $z_{\mathrm{B}}$ are the electric charges of the reactants $\mathrm{A}$ and $\mathrm{B}$. Several reactions in the sulfur-oxygen system have been found to obey this relation. ${ }^{6,53}$ In the case of reaction (2) the product $z_{\mathrm{A}} z_{\mathrm{B}}=-2$, leading to an estimate of $k_{2}=3.0 \times 10^{6} \mathrm{dm}^{3} \mathrm{~mol}^{-1} \mathrm{~s}^{-1}$ at $\mu=1$. This value, when used in conjunction with $k_{2} / k_{3}=61.4$, provides $k_{3}=4.9 \times 10^{4} \mathrm{dm}^{3} \mathrm{~mol}^{-1} \mathrm{~s}^{-1}$. In addition, the combination with the ratios $k_{3} / k_{4}=42$ and $k_{6} / k_{2}=0.27$ leads to $k_{4}=2.1 \times 10^{6}$ and $k_{6}=8.1 \times 10^{5} \mathrm{dm}^{3} \mathrm{~mol}^{-1} \mathrm{~s}^{-1}$. These values must be considered estimates, and confirmation by direct measurements will be needed.

According to eqn (11) the overall rate coefficient $k_{3}$ is a $\mathrm{pH}$-dependent average of $k_{3 \mathrm{a}}$ and $k_{3 \mathrm{~b}}$. If the reaction of $\mathrm{SO}_{3}{ }^{-}$ with $\mathrm{Fe}^{3+}$ were dominant, the value derived above for $k_{3}$ would refer to $k_{3 \mathrm{a}}$. Alternatively, if the reaction proceeded via $\mathrm{FeOH}^{2+}$, $k_{3} \approx k_{3 \mathrm{~b}} K_{\mathrm{h} 1} /\left[\mathrm{H}^{+}\right]$. In this case $k_{3 \mathrm{~b}} \approx 7.6 \times 10^{6} \mathrm{dm}^{3} \mathrm{~mol}^{-1} \mathrm{~s}^{-1}$ at $\mu=1.0$. The experimental data, ${ }^{10-12}$ especially those of Carlyle and Zeck in Fig. 6a, show little influence of the pH. This would suggest $k_{3}=k_{3 \mathrm{a}}$. But the data points are rather scattered so that they do not allow a clear choice between the two alternatives. On the other hand, the results discussed further below, obtained at higher $\mathrm{pH}$, indicate that reaction $(3 \mathrm{~b})$ is important. In analyzing these data both possibilities will be considered, but the issue clearly is not resolved and will require further scrutiny.

\section{Results from studies at higher $\mathrm{pH}$}

The preceding discussion referred to data obtained at low $\mathrm{pH}$ under conditions where the $\mathrm{FeSO}_{3}{ }^{+}$complex is dominant and higher complexes can be neglected. When the $\mathrm{pH}$ is raised, this condition no longer holds and the presence of the higher $\mathrm{Fe}(\mathrm{III})-\mathrm{S}(\mathrm{Iv})$ complexes must be taken into account. At higher $\mathrm{pH}$ the reaction also proceeds much more rapidly so that it cannot be studied by conventional techniques. Thus, Conklin and Hoffmann ${ }^{14}$ and Kraft and van Eldik ${ }^{15}$ have used spectrophotometry to follow the decay of the complexes with time, whereas Millero et al. ${ }^{54}$ applied micro-molar concentrations of $\mathrm{Fe}(\mathrm{III})$ and $\mathrm{S}$ (Iv) to extend the time scale of observation to $80 \mathrm{~min}$. The latter authors unfortunately worked with seawater or concentrated $\mathrm{NaCl}$ solutions as solvents, which led to the formation of various other Fe(III) complexes in addition to those between iron and sulfite, This makes the system difficult to interpret. In fact, the observed rate coefficients were by orders of magnitude greater than those found in other studies.

The presence of higher $\mathrm{Fe}(\mathrm{III})-\mathrm{S}$ (IV) complexes requires an extension of the reaction mechanism in Table 1 because similar to $\mathrm{FeSO}_{3}{ }^{+}$these complexes may also decompose and react with $\mathrm{SO}_{3}{ }^{-}$radicals. For the purpose of discussion the additional reactions may be defined as follows:

$$
\begin{gathered}
\mathrm{Fe}\left(\mathrm{SO}_{3}\right)_{2}{ }^{-} \rightarrow \mathrm{Fe}^{2+}+\mathrm{SO}_{3}{ }^{2-}+\mathrm{SO}_{3}{ }^{-} \\
\mathrm{Fe}\left(\mathrm{SO}_{3}\right)_{3} \mathrm{H}^{2-} \rightarrow \mathrm{Fe}^{2+}+\mathrm{SO}_{3}{ }^{2-}+\mathrm{HSO}_{3}{ }^{-}+\mathrm{SO}_{3}{ }^{-} \\
\mathrm{Fe}\left(\mathrm{SO}_{3}\right)_{2}{ }^{-}+\mathrm{SO}_{3}{ }^{-} \rightarrow \mathrm{Fe}^{2+}+\mathrm{S}_{2} \mathrm{O}_{6}{ }^{2-}+\mathrm{SO}_{3}{ }^{2-} \\
\mathrm{Fe}\left(\mathrm{SO}_{3}\right)_{3} \mathrm{H}^{2-}+\mathrm{SO}_{3}{ }^{-} \rightarrow \mathrm{Fe}^{2+}+\mathrm{S}_{2} \mathrm{O}_{6}{ }^{2-}+\mathrm{HSO}_{3}{ }^{-}+\mathrm{SO}_{3}{ }^{2-}
\end{gathered}
$$

The reaction rate will be determined by an equation similar to eqn (10), where now $\left[\mathrm{Fe}_{\mathrm{III}}\right]=\left[\mathrm{Fe}^{3+}\right]+\left[\mathrm{FeOH}^{2+}\right]+\left[\mathrm{FeSO}_{3}{ }^{+}\right]+$ $\left[\mathrm{Fe}\left(\mathrm{SO}_{3}\right)_{2}{ }^{-}\right]+\left[\mathrm{Fe}\left(\mathrm{SO}_{3}\right)_{3} \mathrm{H}^{2-}\right]$ and $k_{1}$ and $k_{4}$ must be replaced by the weighted total rate coefficients $k_{1 \text { tot }}=k_{1} f_{1}+k_{1 \mathrm{a}} f_{2}+k_{1 \mathrm{~b}} f_{3}$ and $k_{4 \text { tot }}=k_{4} f_{1}+k_{4 \mathrm{a}} f_{2}+k_{4 \mathrm{~b}} f_{3}$, respectively, where the $f_{i}$ denote the corresponding fractions of the three iron-sulfito complexes. Since the relative abundance of the three complexes is a function of the $\mathrm{pH}$, the product distribution and the reaction rate are expected to vary accordingly. Although appropriate measurements should, in principle, provide information on the participation of each complex in the overall reaction, the available data are fragmentary, and measurements of the product distributions are almost totally lacking.

Conklin and Hoffmann ${ }^{14}$ have studied the reaction at $\mathrm{pH} 2$ and $\mu=1.0 \mathrm{~mol} \mathrm{dm}{ }^{-3}$ in the presence of formic acid. They used spectrophotometry at $\lambda=350 \mathrm{~nm}$ to monitor the decay of the absorbance resulting from the sum of Fe(III) species. Formic acid forms a complex with Fe(III), which ties up a considerable fraction of $\mathrm{Fe}$ (III) so that the concentration of free Fe(III) and the reaction rate are markedly reduced compared to values in the absence of formic acid. Hence, the time period of the decay extends for hours rather than seconds or minutes as in the absence of formic acid. According to Biruš et al. ${ }^{50}$ the formation of the $\mathrm{FeOOCH}^{2+}$ complex proceeds via $\mathrm{FeOH}^{2+}$ and $\mathrm{HCOOH}$ as reactants, but the only reliable value for the stability constant, $K_{\text {cfa }}=1.26 \times 10^{3} \mathrm{dm}^{3} \mathrm{~mol}^{-1}$, reported by Perrin ${ }^{32}$ at $\mu=1.0$ and $25{ }^{\circ} \mathrm{C}$, refers to the formation from $\mathrm{Fe}^{3+}$ and $\mathrm{HCOO}^{-}$:

$$
\begin{gathered}
\mathrm{FeOH}^{2+}+\mathrm{HCOOH}=\mathrm{FeOOCH}^{2+}+\mathrm{H}_{2} \mathrm{O} \\
\mathrm{Fe}^{3+}+\mathrm{HCOO}^{-}=\mathrm{FeOOCH}^{2+} \\
K_{\mathrm{cf}}=\left[\mathrm{FeOOCH}^{2+}\right] /\left[\mathrm{FeOH}^{2+}\right][\mathrm{HCOOH}] \\
K_{\mathrm{cfa}}=\left[\mathrm{FeOOCH}^{2+}\right] /\left[\mathrm{Fe}^{3+}\right]\left[\mathrm{HCOO}^{-}\right]
\end{gathered}
$$


Both equilibrium constants are related in that $K_{\mathrm{cf}}=K_{\mathrm{cfa}} K_{\mathrm{d} 4} / K_{\mathrm{h} 1}$. Here, $K_{\mathrm{d} 4}=2.95 \times 10^{-4} \mathrm{~mol} \mathrm{dm}^{-3}$ is the dissociation constant of formic acid at $\mu=1.0 .^{55}$ Accordingly, $K_{\mathrm{cf}}=2.2 \times 10^{2} \mathrm{dm}^{3} \mathrm{~mol}^{-1}$. Rate coefficients for the formation and decomposition of the complex as estimated by Moorhead and $\operatorname{Sutin}^{56}$ are $2.5 \times$ $10^{3} \mathrm{dm}^{3} \mathrm{~mol}^{-1} \mathrm{~s}^{-1}$ and $11 \mathrm{~s}^{-1}$, respectively. The values are large enough to guarantee that the equilibrium between free $\mathrm{Fe}(\mathrm{III})$ and the $\mathrm{FeOOCH}^{2+}$ complex is maintained during the $\mathrm{Fe}(\mathrm{III})-\mathrm{S}$ (Iv) reaction.

Fig. 11 shows two of the absorbance decay curves observed by Conklin and Hoffmann. ${ }^{14}$ Computer calculations were carried out with the aim to reproduce these decay curves. Absorption coefficients required in the calculations were estimated from the absorbance data given by the authors at $\lambda=350 \mathrm{~nm}$ as a function of $\left[\mathrm{S}_{\mathrm{IV}}\right]$ (their Fig. 3a). These data were evaluated by calculating the changes in the distribution of $\mathrm{Fe}(\mathrm{III})-\mathrm{S}$ (Iv) complexes under the particular conditions applied in these experiments, and the estimated absorption coefficients were adjusted until agreement was reached between calculated and observed absorbances. The coefficients derived are $\varepsilon\left(\mathrm{FeSO}_{3}{ }^{+}\right) \approx 290, \varepsilon\left(\mathrm{Fe}\left(\mathrm{SO}_{3}\right)_{2}{ }^{-}\right) \approx 740$, $\varepsilon\left(\mathrm{Fe}\left(\mathrm{SO}_{3}\right)_{3} \mathrm{H}^{2-}\right) \approx 750 \mathrm{dm}^{3} \mathrm{~mol}^{-1} \mathrm{~cm}^{-1} ; \varepsilon\left(\mathrm{FeOH}^{2+}\right)=630$ and $\varepsilon\left(\mathrm{FeSO}_{4}{ }^{+}\right)=576$ at $\lambda=350 \mathrm{~nm}$ are known from previously work. ${ }^{26}$ The absorbances calculated with these data for the distributions of $\mathrm{Fe}$ (III) species at the start of the reaction under the experimental conditions used in Fig. 11 did not quite reproduce the observed initial values. However, the $\mathrm{FeOOCH}^{2+}$ complex is known to be photochemically active, ${ }^{57,58}$ and it is expected to contribute to the total absorbance at wavelengths near $350 \mathrm{~nm}$. An absorption coefficient of $\varepsilon\left(\mathrm{FeOOCH}^{2+}\right) \approx 170$ was found to close the gap and to bring calculated and observed initial absorbances into agreement. This value is similar in magnitude to that estimated by Baxendale and Bridge ${ }^{57}$ at $\lambda=365 \mathrm{~nm}$ : $\varepsilon\left(\mathrm{FeOOCH}^{2+}\right) \approx 100 \mathrm{dm}^{3} \mathrm{~mol}^{-1} \mathrm{~cm}^{-1}$.

The experimental data shown in Fig. 11 refer to two initial

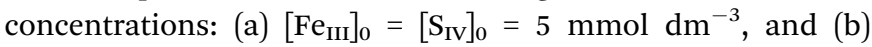
$\left[\mathrm{Fe}_{\mathrm{III}}\right]_{0}=4$ and $\left[\mathrm{S}_{\mathrm{IV}}\right]_{0}=20 \mathrm{mmol} \mathrm{dm}{ }^{-3}$. The calculated equilibrium distributions indicate that in the first case about $95 \%$ of total iron is bound to the FeOOCH${ }^{2+}$ complex, in the second case it is about $84 \%$. These fractions do not greatly vary during the reaction. The distributions of the remaining Fe(III) species and their changes as the reaction proceeds are indicated in the two lower frames of Fig. 11. In the first case the $\mathrm{FeSO}_{3}{ }^{+}$complex is dominant, in the second case $\left(\mathrm{Fe}\left(\mathrm{SO}_{3}\right)_{3} \mathrm{H}^{2-}\right)$ is more abundant. It was expected that the simple mechanism in Table 1 would suffice to reproduce the decay of absorbance in the first case, while in the second case the mechanism would have to be extended to include reactions of the $1: 3$-complex. The computer calculations first showed that the experimental data can be reproduced only by assuming that reaction $(3 \mathrm{~b})$ is the main channel of reaction (3) with $k_{3 \mathrm{~b}}=7.6 \times 10^{6} \mathrm{dm}^{3} \mathrm{~mol}^{-1} \mathrm{~s}^{-1}$

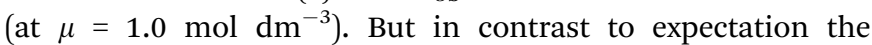
calculations also showed that the basic mechanism of Table 1 is adequate to reproduce both sets of experimental data. The results are shown in Fig. 11 by the solid lines. The assumption of even a minimal contribution by the decomposition of the 1:3-complex only worsened the agreement between calculated

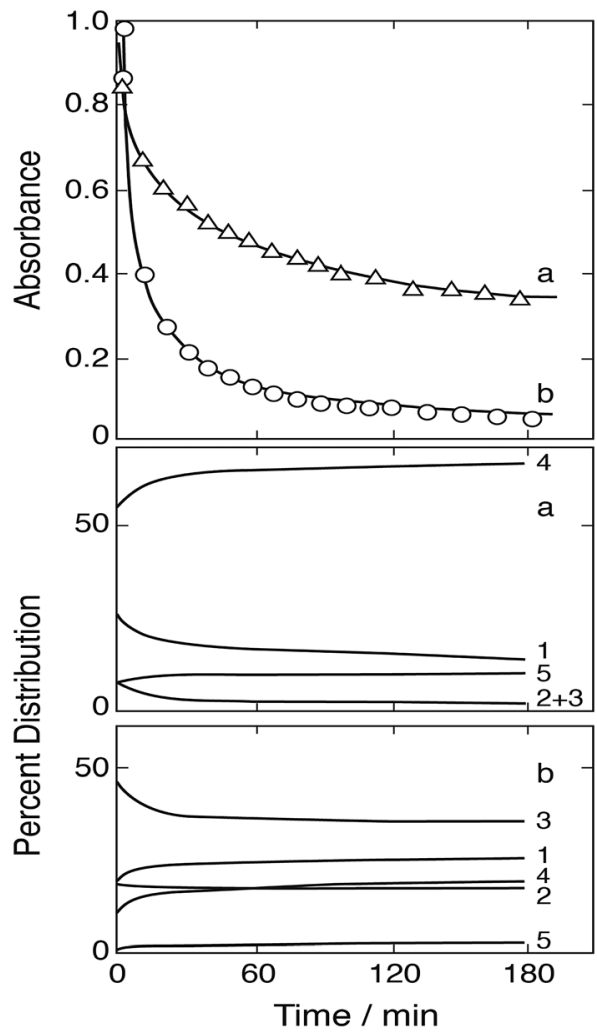

Fig. $11 \mathrm{Fe}\left(\right.$ III) $-\mathrm{S}$ (IV) reaction in the presence of $1 \mathrm{~mol} \mathrm{dm}^{-3}$ of formic acid, $\mathrm{pH} 2, \mu=1.0$ (Conklin and Hoffmann ${ }^{14}$ ). Upper frame: Points are measurements of the absorbance due to $\mathrm{Fe}(\mathrm{III})$ species at $350 \mathrm{~nm}$; (a) $\left[\mathrm{Fe}_{I I I}\right]_{0}=$ $\left[\mathrm{S}_{\mathrm{IV}}\right]_{0}=5 \mathrm{mmol} \mathrm{dm}{ }^{-3}$, (b) $\left[\mathrm{Fe}_{I I I}\right]_{0}=4$ and $\left[\mathrm{S}_{\mathrm{IV}}\right]_{0}=20 \mathrm{mmol} \mathrm{dm}^{-3}$; the solid lines were calculated (see text for details). Lower frames: Change with time of the associated equilibrium distributions of $\mathrm{Fe}(\mathrm{III})$ species (exclusive of $\mathrm{FeOOCH}^{2+}$, , (1) $\mathrm{FeSO}_{3}{ }^{+}$, (2) $\mathrm{Fe}\left(\mathrm{SO}_{3}\right)_{2}{ }^{-}$, (3) $\mathrm{FeH}\left(\mathrm{SO}_{3}\right)_{3}^{2-}$, (4) $\mathrm{Fe}^{3+}$, (5) $\mathrm{FeOH}^{2+}$

and experimental data in that the initial decay rate became too rapid. The rate coefficient for the decomposition was estimated to be $k_{1 \mathrm{~b}}<0.01 \mathrm{~s}^{-1}$. These results suggest that under the experimental conditions chosen the 1:3-complex does not significantly participate in the reaction.

The experimental data in Fig. 11 were also subjected to tests for first and/or second order reaction behavior. A first order decay was found to occur only in the very initial stage of the reaction. There follows a transition period, which is apparent in Fig. 11 by an adjustment of the distributions of Fe(III) species, until after about 20 min the decay of absorbance shows second order behavior. Conklin and Hoffmann ${ }^{14}$ had tried to fit the observed decay curves by a rate expression with two consecutive exponential terms. This procedure provides only a coarse description of the experimental data, and it is in conflict with the present mechanism and its steady state description in eqn (10).

Kraft and van Eldik ${ }^{15}$ have analyzed absorbance decay curves obtained at $\lambda=390 \mathrm{~nm}, \mu=0.1 \mathrm{~mol} \mathrm{dm}^{-3}$ under various experimental conditions. They described decay curves only in general terms, ${ }^{17}$ but did not present the original data. Following Conklin and Hoffmann, they interpreted the observed kinetic behavior as that of two consecutive reactions and reported 
apparent first order rate coefficients, one for the initial, and the second for a later stage of the reaction (stages III and IV in their notation). The preceding discussion has shown, however, that the true origin of the observed kinetic behavior is that of a shift from first to second order and not, for example, the decomposition of complexes occurring in parallel at different rates. Accordingly, only the first of the two apparent rate coefficients can be useful, whereas the second defies a meaningful analysis. No details were given about how the rate coefficients were determined. The authors state that a standard least-square fitting program was used ${ }^{17}$ in the data evaluation, but the time periods for the averaging process were not specified.

Computer calculations were performed with the aim to reproduce the apparent first order rate coefficients reported for the initial section of the decay curve. As the measured quantity is the absorbance $A$, the apparent rate coefficients are defined as $k=-\mathrm{d} A / A \mathrm{~d} t$ or, in integrated form, $k=(1 / \Delta t) \ln \left(A_{1} / A_{2}\right)$ with $\Delta t=t_{2}-t_{1}$. Both expressions were explored, with little difference in the results $(\Delta t=1 \mathrm{~s})$. Fig. 5 had shown that the various $\mathrm{Fe}(\mathrm{III})$ species come to equilibrium at $t \approx 0.2 \mathrm{~s}$ and this sets a lower limit to $t_{1}$. The decomposition of iron-sulfito complexes begins before the equilibrium is fully achieved. All results show that the reaction can be truly of first order only at very short reaction times. Due to the rapidity of the reaction sufficient $\mathrm{Fe}^{2+}$ develops early in the process to activate the back-reaction $\mathrm{SO}_{3}{ }^{-}+\mathrm{Fe}^{2+} \rightarrow \mathrm{FeSO}_{3}{ }^{+}$whereupon the reaction rate decreases. This is evident also during the time period available to calculate apparent first order rate coefficients. Here, the time period was confined to the range 0.5-4 $\mathrm{s}$. At longer times the values obtained are markedly lowered while the calculated standard deviation of the averages increases.

Absorption coefficients at $\lambda=390 \mathrm{~nm}$ for the three complexes and $\varepsilon\left(\mathrm{FeOH}^{2+}\right)$ were derived earlier (see under Absorption coefficients), and $\varepsilon\left(\mathrm{FeSO}_{4}^{+}\right) \approx 100 \mathrm{dm}^{3} \mathrm{~mol}^{-1} \mathrm{~cm}^{-1}$ was obtained by extrapolation of published data; ${ }^{26}$ the contribution by $\mathrm{Fe}^{3+}$ to the absorbance can be neglected. The calculations made use of the reaction rate coefficients derived in the preceding section. They were adjusted to the difference in ionic strength $(\mu=0.1)$, which leads to $k_{1}=0.19 \mathrm{~s}^{-1}, k_{2}=1.0 \times 10^{7}, k_{3 \mathrm{a}} \leq 3.0 \times 10^{5}$, $k_{3 \mathrm{~b}} \leq 2.6 \times 10^{7}, k_{4} \approx 4.0 \times 10^{6}\left(\mathrm{dm}^{3} \mathrm{~mol}^{-1} \mathrm{~s}^{-1}\right)$. Additional rate coefficients for reactions involving the $1: 2$ - and $1: 3$-complexes were then introduced on a trial basis as needed to bring observed and calculated data to agreement.

Kraft and van Eldik $^{15}$ reported results for three series of experiments. Two series were performed at $\mathrm{pH}$ 2.5: (a) $\left[\mathrm{S}_{\mathrm{IV}}\right]_{0}=$ $1.25 \mathrm{mmol} \mathrm{dm}{ }^{-3}$ was kept constant and $\left[\mathrm{Fe}_{\mathrm{III}}\right]_{0}$ was varied between 0.25 and $6.0 \mathrm{mmol} \mathrm{dm}{ }^{-3}$; (b) $\left[\mathrm{Fe}_{\text {III }}\right]_{0}=0.5 \mathrm{mmol} \mathrm{dm}^{-3}$ was kept constant and $\left[\mathrm{S}_{\mathrm{IV}}\right]_{0}$ was varied between 0.1 and $3.0 \mathrm{mmol} \mathrm{dm}{ }^{-3}$; (c) in the third series $\left[\mathrm{Fe}_{\mathrm{III}}\right]_{0}=0.5$ and $\left[\mathrm{S}_{\mathrm{IV}}\right]_{0}=20 \mathrm{mmol} \mathrm{dm}^{-3}$ were kept constant and the $\mathrm{pH}$ was varied between 1.3 and 2.9. The results of series (a) show that the apparent first order rate coefficient initially decreases with increasing $\mathrm{Fe}(\mathrm{III})$ until, when $\left[\mathrm{Fe}_{\mathrm{III}}\right]_{0} \geq 2.0 \mathrm{mmol} \mathrm{dm}^{-3}$, an essentially constant value is reached, with a reported average $k_{\text {app }}=(0.054 \pm 0.04) \mathrm{s}^{-1}$ in the range $\left[\mathrm{Fe}_{\mathrm{III}}\right]_{0}=2-6 \mathrm{mmol} \mathrm{dm}^{-3}$. In this region the $\mathrm{FeSO}_{3}{ }^{+}$complex is dominant and contributions of the two higher complexes can be neglected. Calculations of the apparent first order rate coefficient were performed for two limiting cases of $k_{3}$, setting either $k_{3 \mathrm{a}}=3.0 \times 10^{5}$ and $k_{3 \mathrm{~b}}=0$ or $k_{3 \mathrm{~b}}=2.6 \times 10^{7}$ and $k_{3 \mathrm{a}}=0\left(\mathrm{dm}^{3} \mathrm{~mol}^{-1} \mathrm{~s}^{-1}\right)$. Average $k_{\text {app }}$ values obtained for $\left[\mathrm{Fe}_{\mathrm{III}}\right]_{0}=2,4$, and $6 \mathrm{mmol} \mathrm{dm}{ }^{-3}$ were $0.067 \pm$ $0.013 \mathrm{~s}^{-1}$ in the first case, and $0.090 \pm 0.012 \mathrm{~s}^{-1}$ in the second (9 data points each). The former result is closer to the value reported than the latter, suggesting that reaction $(3 \mathrm{~b})$ is not the sole channel of reaction (3).

The upper frame of Fig. 12 shows apparent initial first order rate coefficients obtained when $\left[\mathrm{S}_{\mathrm{IV}}\right]_{0}$ was varied and $\left[\mathrm{Fe}_{\mathrm{III}}\right]_{0}$ was kept constant. ${ }^{15}$ The rate coefficient first rises with increasing $\left[\mathrm{S}_{\mathrm{IV}}\right]_{0}$ and then approaches a constant value of $k_{\mathrm{app}} \approx 0.135 \mathrm{~s}^{-1}$. The lower frame of the figure shows the corresponding change in the calculated distribution of $\mathrm{Fe}$ (III) species. As the S(Iv) concentration is raised, the distribution shifts from $\mathrm{FeSO}_{3}{ }^{+}$to $\mathrm{Fe}\left(\mathrm{SO}_{3}\right)_{3} \mathrm{H}^{2-}$ as the major species. The observation that the apparent rate coefficient still remains at a high value is a clear indication that the $1: 3$-complex is subject to decomposition and that it participates in the reaction. Computer calculations were performed in attempts to reproduce the observed variation in the $k_{\text {app }}$ values. The solid line shown in the upper part of Fig. 12 was obtained with the rate coefficients given above and the assumption that $k_{1 \mathrm{a}}=0.04 \mathrm{~s}^{-1}, k_{1 \mathrm{~b}}=0.08 \mathrm{~s}^{-1}$ for the decomposition of the 1:2- and 1:3-complexes, respectively, and $k_{4 \mathrm{~b}}=1.2 \times 10^{7} \mathrm{dm}^{3} \mathrm{~mol}^{-1} \mathrm{~s}^{-1}$ for the reaction of $\mathrm{SO}_{3}{ }^{-}$ radicals with the $1: 3$-complex. The initial rise curve was better represented with $k_{3 \mathrm{~b}}=2.6 \times 10^{7} \mathrm{dm}^{3} \mathrm{~mol}^{-1} \mathrm{~s}^{-1}$ rather than with $k_{3 \mathrm{a}}=3.0 \times 10^{5} \mathrm{dm}^{3} \mathrm{~mol}^{-1} \mathrm{~s}^{-1}$ and $k_{3 \mathrm{~b}}=0$ (shown by the broken line). The experimental data indicate a slight overshoot at $\left[\mathrm{S}_{\mathrm{IV}}\right]_{0} \approx 5 \mathrm{mmol} \mathrm{dm}^{-3}$, which could be reproduced, if the value chosen for $k_{4}$ were raised by $50 \%$. Fig. 13 shows the variation of the apparent initial first order rate coefficients with the $\mathrm{pH}$ and,

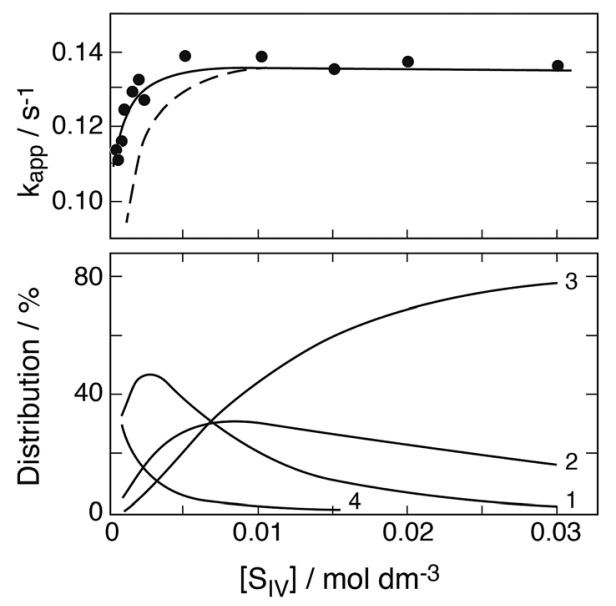

Fig. 12 Upper frame: Apparent initial first order rate coefficient as a function of $\left[\mathrm{S}_{\mathrm{IV}}\right]_{0},\left[\mathrm{Fe}_{\mid I I I}\right]_{0}=0.5 \mathrm{mmol} \mathrm{dm}{ }^{-3}, \mathrm{pH} 2.5, \mu=0.1$; points are measurements (Kraft and van Eldik ${ }^{15}$ ), the solid line represents computerbased calculations with $k_{3 b}=2.6 \times 10^{7} \mathrm{dm}^{3} \mathrm{~mol}^{-1} \mathrm{~s}^{-1}$ (see text for details), the broken line results with $k_{3 a}=3.0 \times 10^{5} \mathrm{dm}^{3} \mathrm{~mol}^{-1} \mathrm{~s}^{-1}, k_{3 b}=0$. Lower frame: Equilibrium distributions of $\mathrm{Fe}(\mathrm{III})$ species at the beginning of the reaction: (1) $\mathrm{FeSO}_{3}^{+}$, (2) $\mathrm{Fe}\left(\mathrm{SO}_{3}\right)_{2}{ }^{-}$, (3) $\mathrm{Fe}\left(\mathrm{SO}_{3}\right)_{3} \mathrm{H}^{2-}$, (4) $\mathrm{FeOH}^{2+} \approx \mathrm{Fe}^{3+}$. 


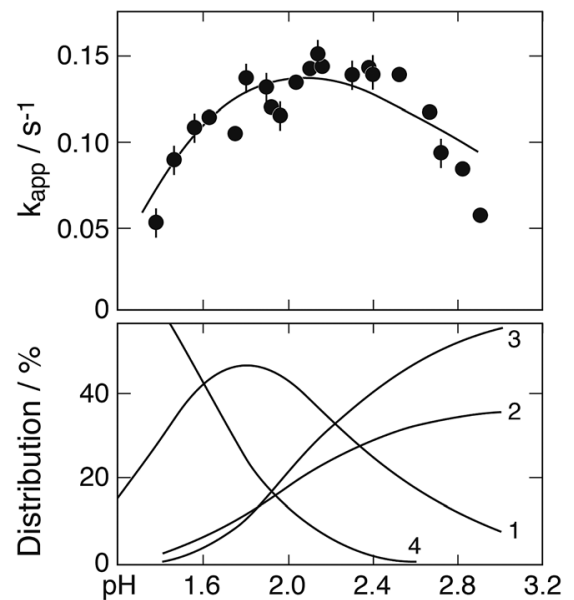

Fig. 13 Upper frame: Apparent initial first order rate coefficient as a function of $\mathrm{pH},\left[\mathrm{Fe}_{\mathrm{II}}\right]_{0}=0.5,\left[\mathrm{~S}_{\mathrm{IV}}\right]_{0}=10 \mathrm{mmol} \mathrm{dm}{ }^{-3}, \mu=0.1$; points are measurements (Kraft and van Eldik ${ }^{15}$ ), the line represents computer-based calculations (see text for details). Lower frame: Equilibrium distributions of $\mathrm{Fe}(\mathrm{III})$ species at the beginning of the reaction: (1) $\mathrm{FeSO}_{3}{ }^{+}$, (2) $\mathrm{Fe}\left(\mathrm{SO}_{3}\right)_{2}{ }^{-}$, (3) $\mathrm{Fe}\left(\mathrm{SO}_{3}\right)_{3} \mathrm{H}^{2-}$, (4) $\mathrm{Fe}^{3+}$.

in the lower part of the figure, the change in the equilibrium distribution of $\mathrm{Fe}(\mathrm{III})$ species. The distribution shifts from $\mathrm{FeSO}_{3}{ }^{+}$to $\mathrm{Fe}\left(\mathrm{SO}_{3}\right)_{3} \mathrm{H}^{2-}$ as the $\mathrm{pH}$ is raised, indicating again that the higher complexes participate in the overall reaction. Computer calculations performed in attempts to reproduce the observed variation in the $k_{\text {app }}$ values showed that in this case the results differed little with the choice of $k_{3}$ (either $k_{3 \mathrm{~b}}=$ $2.6 \times 10^{7}$ or $k_{3 \mathrm{a}}=3.0 \times 10^{5} \mathrm{dm}^{3} \mathrm{~mol}^{-1} \mathrm{~s}^{-1}$ and $\left.k_{3 \mathrm{~b}}=0\right)$. The solid line shown in the upper part of Fig. 13 was calculated with the rate coefficients given above and the assumption that $k_{1 \mathrm{a}}=0.04 \mathrm{~s}^{-1}, k_{1 \mathrm{~b}}=0.06 \mathrm{~s}^{-1}$ for the decomposition of the $1: 2$ - and 1:3-complexes, respectively, and $k_{4 \mathrm{~b}}=1.2 \times$ $10^{7} \mathrm{dm}^{3} \mathrm{~mol}^{-1} \mathrm{~s}^{-1}$ for the reaction of $\mathrm{SO}_{3}{ }^{-}$radicals with the 1:3-complex. These values are quite similar to those found applicable in the preceding case when the $\mathrm{pH}$ was kept constant and $\left[\mathrm{S}_{\mathrm{IV}}\right]_{0}$ was varied. Above $\mathrm{pH} 2.5$ it was not possible to obtain a good fit between calculated and observed $k_{\text {app }}$ values.

The overall result of the computer simulations is the recognition that all three complexes undergo decomposition, but the decomposition rates for the two higher complexes are markedly lower than that for the $1: 1$-complex $\left(k_{1 \mathrm{a}} \approx 0.04 \mathrm{~s}^{-1}\right.$ and $k_{1 \mathrm{~b}} \approx 0.08 \mathrm{~s}^{-1}$ compared to $k_{1}=0.19 \mathrm{~s}^{-1}$ ). This conclusion obviously disagrees with that derived above in evaluating the data of Conklin and Hoffmann, ${ }^{14}$ which had indicated that the $1: 2$ and $1: 3$ iron-sulfito complexes do not significantly participate in the reaction. The major difference in the applied experimental conditions, apart from the presence of formic acid in the latter case, is the difference in ionic strength $(\mu=0.1$ versus $\mu=1.0$ ). This may have a bearing on the reaction rate coefficients, but it should not affect the decomposition rates.

Kraft and van Eldik ${ }^{\mathbf{1 5}}$ have also used ion chromatography to determine the yields of sulfate and dithionate after a reaction time of $5 \mathrm{~min}$ and $40 \mathrm{~min}$, respectively. The initial concentration of iron was $\left[\mathrm{Fe}_{\mathrm{III}}\right]_{0}=0.5 \mathrm{mmol} \mathrm{dm}{ }^{-3},\left[\mathrm{~S}_{\mathrm{IV}}\right]_{0}$ was varied from 0.5 to $5.0 \mathrm{mmol} \mathrm{dm}^{-3}$. The average $\mathrm{pH}$ was 3.47 (range 3.30-3.56). The ionic strength was not controlled but it is estimated to approximate to $\mu \approx 0.006$. These data are needed to calculate the equilibrium constants involved and to determine the equilibrium distribution of the Fe(III) species. At $\mathrm{pH}$ 3.5 the contribution of $\mathrm{Fe}_{3}{ }^{+}$to the sum of $\mathrm{Fe}(\mathrm{III})$ hydrolysis products is almost negligible, but that of $\mathrm{Fe}(\mathrm{OH})_{2}{ }^{+}$cannot be ignored as Fig. 2 showed. $\mathrm{Fe}(\mathrm{OH})_{2}{ }^{+}$is expected to react with $\mathrm{HSO}_{3}{ }^{-}$in a similar way as $\mathrm{Fe}(\mathrm{OH})^{2+}$ to form an $\mathrm{Fe}(\mathrm{III})-\mathrm{S}$ (IV) complex, but this reaction has not yet been explored and no definite knowledge exists about the nature of the complex. Both $\mathrm{FeOHSO}_{3}$ and $\mathrm{FeSO}_{3}{ }^{+}$may be formed. In order to allow an analysis of the product yields it will be assumed that $\mathrm{Fe}(\mathrm{OH})_{2}{ }^{+}$ reacts like $\mathrm{Fe}(\mathrm{OH})^{2+}$ so that both species can be combined. The upper part of Fig. 14 shows the yields of dithionate reported by Kraft and van Eldik $^{15}$ as a function of $\left[\mathrm{S}_{\mathrm{IV}}\right]_{0}$, the lower part shows the calculated distribution of $\mathrm{Fe}(\mathrm{III})$ species. The rise of dithionate yield with increasing $\left[\mathrm{S}_{\mathrm{IV}}\right]_{0}$ is accompanied by a rise in the relative concentrations of the $1: 2$ - and $1: 3$-complexes, whereas that of the sum of $\mathrm{Fe}(\mathrm{OH})^{2+}$ and $\mathrm{Fe}(\mathrm{OH})_{2}{ }^{+}$decreases.

In contrast to the experimentally observed rise in the yield of dithionate with increasing $\left[\mathrm{S}_{\mathrm{IV}}\right]_{0}$ Kraft and van Eldik found the yield of sulfate to stay nearly constant, ${ }^{15}$ decreasing slightly from 0.33 to $0.26 \mathrm{mmol} \mathrm{dm}{ }^{-3}$. If the results for sulfate were correct, the sum of both product yields would significantly

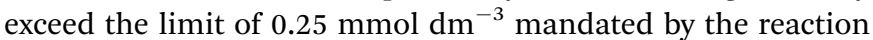
mechanism ( $c f$. eqn (10a)). It appears, therefore, that the data for sulfate are spoiled by the presence of an impurity introduced with one of the solutions used to make up the reaction mixture. The occurrence of dithionate as an impurity is rather unlikely so that the measured concentrations of dithionate are taken to provide true yields.

In the foregoing, the reaction of $\mathrm{SO}_{3}{ }^{-}$radicals with the $\mathrm{FeSO}_{3}{ }^{+}$complex was shown to be the only source of dithionate,

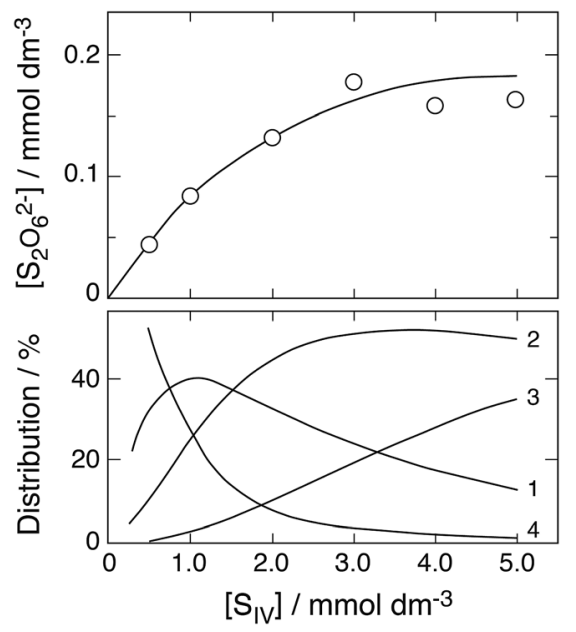

Fig. 14 Upper frame: Points show the measured yield of dithionate (Kraft and van Eldik $\left.{ }^{15}\right)$ as a function of $\left[\mathrm{S}_{\mathrm{IV}}\right]_{0}\left(\left[\mathrm{Fe}_{\mid I I}\right]_{0}=0.5 \mathrm{mmol} \mathrm{dm}{ }^{-3}\right)$, the solid line shows results of computer calculation based on the competition of reactions (3b) and (4). Lower frame: Equilibrium distribution of $\mathrm{Fe}($ (II) species at the beginning of the reaction (1) $\mathrm{FeSO}_{3}{ }^{+}$, (2) $\mathrm{Fe}\left(\mathrm{SO}_{3}\right)_{2}{ }^{-}$, (3) $\mathrm{Fe}\left(\mathrm{SO}_{3}\right)_{3} \mathrm{H}^{2-}$, (4) sum of $\mathrm{FeOH}^{2+}$ and $\mathrm{Fe}(\mathrm{OH})_{2}{ }^{+}$. 
but the extended reaction mechanism would allow this product to be formed also in reactions of $\mathrm{SO}_{3}{ }^{-}$radicals with one of the two higher complexes. This possibility was explored by means of computer simulations. The individual rate coefficients used in this case were obtained by an appropriate adjustment to the lower ionic strength $\mu=0.006$ in these experiments. It was confirmed that at low $\left[\mathrm{S}_{\mathrm{IV}}\right]$ concentrations, where $\mathrm{FeSO}_{3}{ }^{+}$contributes significantly to the mix of $\mathrm{Fe}(\mathrm{III})$ species, reaction (4) remains the most important source of dithionate. The rise of the dithionate yield with increasing $\left[\mathrm{S}_{\mathrm{IV}}\right]_{0}$ must then be due to a competing reaction (leading to sulfate). Reaction (3a) will be unimportant at $\mathrm{pH} 3.4$ because the concentration $\left[\mathrm{Fe}^{3+}\right]$ is too small, but reaction ( $3 \mathrm{~b}$ ) fills the need if the rate coefficient is $k_{3 \mathrm{~b}} \approx 3.0 \times 10^{7} \mathrm{dm}^{3} \mathrm{~mol}^{-1} \mathrm{~s}^{-1}$. The value corresponds approximately to that obtained by extrapolation of the ionic strength to $\mu=0.006$. The equivalent reaction (3c) of $\mathrm{SO}_{3}{ }^{-}$with $\mathrm{Fe}(\mathrm{OH})_{2}{ }^{+}$need not be invoked. A complete set of computer calculations then reveals that reactions (3b) and (4) suffice to reproduce the observed dithionate yields over the whole range of S(Iv) concentrations. The solid line in the upper part of Fig. 14 indicates the extent of agreement reached between observed and calculated yields.

This result does not preclude the participation of higher complexes in the production of dithionate, provided sulfate or another product is formed in a parallel reaction. Trial calculations showed that the 1:2-complex is less likely a source of dithionate than the 1:3-complex, which gains prominence at the high end of the $\mathrm{S}$ (Iv) concentration range. The addition of reaction (4b) with a rate coefficient of $k_{4 \mathrm{~b}} \approx 1.2 \times 10^{7} \mathrm{dm}^{3} \mathrm{~mol}^{-1} \mathrm{~s}^{-1}$ would also provide good agreement with the measured dithionate yields, provided the reaction consisted of two channels, one leading to dithionate with a yield of $65 \%$, the other one leading to sulfate with a yield of $35 \%$. This partitioning determines the plateau of the dithionate concentration at high S(Iv) concentrations. It will be clear that the limited data on dithionate formation reported by Kraft and van Eldik ${ }^{\mathbf{1 5}}$ cannot give definitive answers on all possible routes to dithionate production. However, the recognition that reaction (3b) is more likely in this mechanism than (3a) would be in accord with the conclusions reached in the preceding discussion of the apparent initial first order rate coefficients determined by the authors.

\section{Conclusions}

Three iron-sulfito complexes are formed by the successive addition of $\mathrm{HSO}_{3}{ }^{-}$to $\mathrm{FeOH}^{2+}$. These processes occur rapidly. The subsequent slow reaction is due to the decomposition of the complexes and the formation of $\mathrm{SO}_{3}{ }^{-}$radicals. The decomposition of the 1 :1-complex has been documented, the disintegration of the $1: 2$ - and the $1: 3$-complexes are found to be slower. The mechanism in Table 1 is consistent with most of the data reported for experimental conditions under which the $\mathrm{FeSO}_{3}{ }^{+}$complex is the most abundant intermediate $(\mathrm{pH}<2$, $\left.\left[\mathrm{S}_{\mathrm{IV}}\right] /\left[\mathrm{Fe}_{\mathrm{III}}\right]<200\right)$. However, yields of dithionate reported by different authors diverge significantly, presumably because the classical analytical methods formerly in use were inadequate. Although it was possible to estimate rate coefficients of the reactions involved, the true values will have to be determined in future studies. One of the problems that will require closer attention is the ionic strength dependence of the stability constants of the complexes as well as that of the rate coefficients of the individual reactions.

Finally it important to note that the decomposition of the iron-sulfito complexes discussed in this study initiates the oxidation of S(Iv) also in the presence of oxygen so that the same stability constants and decomposition rates of the complexes will be applicable. But in that case the $\mathrm{SO}_{3}{ }^{-}$radicals are converted to $\mathrm{SO}_{5}{ }^{-}$radicals and the subsequent mechanism takes a different course.

\section{Conflicts of interest}

There are no conflicts of interest to declare.

\section{Acknowledgements}

Open Access funding provided by the Max Planck Society.

\section{References}

1 C. Brandt and R. van Eldik, Chem. Rev., 1995, 95, 119-190 and literature cited therein.

2 P. Warneck, Chemistry of the Natural Atmosphere, 2nd edn, Academic Press, San Diego, 2000, pp. 507-510.

3 E. Harris, B. Sinha, D. van Pinxteren, A. Tilgner, K. W. Fomba, J. Schneider, A. Roth, T. Gnauk, B. Fahlbusch, S. Mertes, T. Lee, J. Collett, S. Foley, S. Borrmann, P. Hoppe and H. Herrmann, Science, 2013, 340, 727-730.

4 K. Bal Reddy and R. van Eldik, Atmos. Environ., 1992, 26A, 661-665.

5 J. Ziajka, F. Beer and P. Warneck, Atmos. Environ., 1994, 28, 2549-2552.

6 G. V. Buxton, S. McGowan, G. A. Salmon, J. E. Williams and N. D. Wood, Atmos. Environ., 1996, 30, 2483-2493.

7 G. V. Buxton, T. N. Malone and G. A. Salmon, J. Chem. Soc., Faraday Trans., 1996, 92, 1287-1289.

8 M. Fischer and P. Warneck, J. Phys. Chem., 1996, 100, 15111-15117.

9 W. C. E. Higginson and J. W. Marshall, J. Chem. Soc., 1957, 447-458.

10 F. H. Pollard, P. Hanson and G. Nickless, J. Chromatogr., 1961, 5, 68-73.

11 D. G. Karraker, J. Phys. Chem., 1963, 67, 871-874.

12 D. W. Carlyle and O. F. Zeck, Inorg. Chem., 1973, 12, 2978-2983.

13 P. K. Dasgupta, P. A. Mitchell and P. W. West, Atmos. Environ., 1979, 13, 775-782.

14 M. H. Conklin and M. R. Hoffmann, Environ. Sci. Technol., 1988, 22, 899-907.

15 J. Kraft and R. van Eldik, Inorg. Chem., 1989, 28, 2306-2312. 
16 G. Lente and I. Fábián,J. Chem. Soc., Dalton Trans., 2002, 778-784. 17 J. Kraft and R. van Eldik, Inorg. Chem., 1989, 28, 2297-2305. 18 E. A. Betterton, J. Atmos. Chem., 1993, 17, 307-324.

19 F. Prinsloo, C. Brandt, V. Lepentsiotis, J. Pienaar and R. van Eldik, Inorg. Chem., 1997, 36, 119-121.

20 E. Danilczuk and A. Swinarski, Rocz. Chem., 1961, 35, 1563-1572.

21 R. M. Milburn and W. C. Vosburgh, J. Am. Chem. Soc., 1955, 77, 1352-1355.

22 R. M. Milburn, J. Am. Chem. Soc., 1957, 79, 537-540.

23 D. H. Richards and K. W. Sykes, J. Chem. Soc., 1960, 3626-3633.

24 A. V. Zotov and Z. Y. Kotova, Geokhimiya, 1979, 285-290.

25 R. S. Sapieszko, R. C. Patel and E. Matijević, J. Phys. Chem., 1977, 77, 1061-1068.

26 H.-J. Benkelberg and P. Warneck, J. Phys. Chem., 1995, 99, 5214-5221.

27 P. Martinez, R. van Eldik and H. Kelm, Ber. Bunsenges. Phys. Chem., 1985, 89, 81-86, the data were reanalyzed.

28 A. Stefansson, Environ. Sci. Technol., 2007, 41, 6117-6123.

29 R. J. Knight and R. N. Sylva, J. Inorg. Nucl. Chem., 1975, 37, 779-783.

30 R. H. Byrne, Y.-R. Luo and R. W. Young, Mar. Chem., 2000, 70, 23-35.

31 B. O. A. Hedström, Archiv. Kemi., 1952, 6, 1-16.

32 D. D. Perrin, J. Chem. Soc., 1959, 1710-1717.

33 L. Lopes, L. de Laat and B. Legube, Inorg. Chem., 2002, 41, 2505-2517.

34 W. N. Perera and G. Hefter, Inorg. Chem., 2003, 42, 5917-5923.

35 R. N. Goldberg and V. B. Parker, J. Res. Natl. Bur. Stand., 1985, 90, 341-358.

36 A. Huss and C. A. Eckert, J. Phys. Chem., 1977, 81, 2268-2270.

37 F. J. Millero, J. P. Hershey, G. Johnson and J.-Z. Zhang, J. Atmos. Chem., 1989, 8, 377-389.

38 T. Sekine, I. Hidehiko, M. Sakairi, F. Shimada and M. Inarida, Bull. Chem. Soc. Jpn., 1968, 41, 1-7.

39 D. Devèze and P. C. Rumpf, C. R. Acad. Sci. Paris, 1964, 258, 6135-6138.

40 M. Frydman, G. Nilsson, T. Rengemo and L. G. Sillen, Acta Chem. Scand., 1958, 12, 878-884.
41 T. W. Newton and G. M. Arcand, J. Am. Chem. Soc., 1953, 75, 2449-2453.

42 Use was made of the computer program of A. R. Curtis, W. P. Sweetenham, Facsimile, UK Atomic Energy Authority, AERE Report R-12805, Harwell, 1987.

43 I. N. Kuzminykh and T. B. Bomshtein, Zh. Prikl. Khim., 1953, 26, 3-8.

44 M. H. Conklin and M. R. Hoffmann, Environ. Sci. Technol., 1988, 22, 883-891.

45 R. M. Smith and A. E. Martell, Critical Stability Constants Inorganic Complexes, Plenum Press, New York, 1976, vol. 4, p. 79.

46 R. L. S. Willix, Trans. Faraday Soc., 1963, 59, 1315-1324.

47 G. V. Buxton, S. Barlow, S. McGowan, G. A. Salmon and J. E. Williams, Phys. Chem. Chem. Phys., 1999, 1, 3111-3115. 48 E. Bjergbakke, Nukleonika, 1979, 24, 825-845.

49 E. Bjergbakke, K. Sehested and O. L. Rasmussen, Radiat. Res., 1979, 66, 433-442.

50 M. Biruš, N. Kujundžić and M. Pribanić, Prog. React. Kinet., 1993, 18, 171-271.

51 M. Eigen, W. Kruse, G. Maass and L. DeMaeyer, Prog. React. Kinet., 1964, 2, 285-318.

52 M. J. Pilling and P. W. Seakins, Reaction Kinetics, Oxford University Press, 1996, pp. 156-158.

53 P. Warneck, Aqueous Solution Chemistry, in Low-Temperature Chemistry in the Atmosphere, ed. G. K. Moortgat, A. J. Barnes, G. Le Bras, J. R. Sodeau, NATO ASI Series I, Springer-Verlag, Berlin, 1994, vol. 21, pp. 175-196.

54 F. J. Millero, M. Gonzales-Davila and J. M. Santana-Casiano, J. Geophys. Res., 1995, 100, 7235-7244.

55 A. E. Martell and R. M. Smith, Critical Stability Constants, Other Organic Ligands, Plenum Press, New York, 1976, vol. 3, p. 1.

56 E. G. Moorhead and N. Sutin, Inorg. Chem., 1966, 5, 1866-1871.

57 J. H. Baxendale and N. K. Bridge, J. Phys. Chem., 1955, 59, 783-788.

58 H. B. Abrahamson, A. B. Rezvani and J. G. Brushmiller, Inorg. Chim. Acta, 1994, 226, 117-127. 